\title{
Optimal Decisions for Contract Farming under Weather Risk
}

\author{
Xinping Wang $\mathbb{D D}^{1}$ and Shengnan Sun $\mathbb{D}^{2}$ \\ ${ }^{1}$ College of Economics and Management, Nanjing Agricultural University, Weigang 1, Nanjing 210095, China \\ ${ }^{2}$ School of Economics and Management, Southeast University, Sipailou 2, Nanjing 210096, China
}

Correspondence should be addressed to Xinping Wang; wangxp@njau.edu.cn

Received 5 August 2021; Revised 22 November 2021; Accepted 17 December 2021; Published 27 January 2022

Academic Editor: Giulio E. Cantarella

Copyright (c) 2022 Xinping Wang and Shengnan Sun. This is an open access article distributed under the Creative Commons Attribution License, which permits unrestricted use, distribution, and reproduction in any medium, provided the original work is properly cited.

\begin{abstract}
Weather risk causes uncertain crop yield and price and further influences the willingness of farmers to participate in contract farming and honour the contract. In this study, we investigate the optimal decisions for contract farming between a profitmaximizing manufacturer and multiple identical farmers under weather risk, using a game-theoretical approach. We discuss two different cases. In the first case, the manufacturer sets a contract price to ensure farmers to honour the contract under any weather condition. While in the second case, the manufacturer sets a lower contract price only to guarantee that farmers will not renege under certain weather condition but has a second chance to purchase products from the reneged farmers at a renegotiated price. We derive the optimal decisions of the manufacturer in both cases and show that the manufacturer gains much more profits in the second case, and therefore, the decisions in the second case are optimal. Moreover, we numerically investigate the sensitivity of the effectiveness of contract farming and the manufacturer's optimal decisions to model parameters and get more managerial implications.
\end{abstract}

\section{Introduction}

Contract farming is widely adopted in developed countries. In recent decades, it has become popular in developing countries such as China, India, and Turkey. Traditionally, farmers produce under their own decisions on variety, quantity, quality, and timing and then sell to the open market. In contrast, contract farming refers to "agricultural production carried out according to an agreement between a firm and farmers, which establishes conditions for the production and marketing of a farm product or products" [1]. Typically, the farmer agrees to provide certain quantities of a specific commodity at the specified quality standards and time, and the firm commits to a specified pricing scheme. In addition, the firm usually provides support to the farmer, for example, fertilizer, pesticide, and technical guidance.

Contract farming brings several benefits to the farmer and the firm. The farmer gets a steady income and obtains access to capital, technology, and information which help to increase yield $[2,3]$. The firm benefits from the relationship as it secures the quantity and quality of the crop. In addition, it helps to reduce or even eliminate certain expenses such as transportation, storage, and spoilage [4]. Emerging empirical evidence shows that this new form of private vertical coordination can be an engine of economic growth, rural development, and poverty reduction [5].

Despite several potential advantages of contract farming, it encounters some challenges in practice. Due to the biological nature of the agricultural production process, contract farming implementation is prone to factors that are uncontrollable, for example, weather, amount of sunlight, and properties of soil. The weather conditions affect the growth of the seed, thereby the quantity and quality of the crops, and it is almost impossible to forecast the weather accurately when making the planting decisions [6]. Bad weather conditions, for example, drought, frost, hail, and extreme temperatures, may reduce the yield of crops sharply [7-9] and lead to supply shortage and price inflation on the spot market, incurring huge losses to the agricultural sector. According to a report from the Food and Agriculture Organization of the United Nations (FAO), between 2005 and 
TABLE 1: Our study vs. the literature.

\begin{tabular}{lccc}
\hline \multirow{2}{*}{ Authors } & $\begin{array}{c}\text { Cethodology } \\
\text { empirical }\end{array}$ & Model & $\begin{array}{c}\text { Considering } \\
\text { weather risk }\end{array}$ \\
\hline Wang et al. [11] & $\checkmark$ & & \\
Wuepper and Sauer [12] & $\checkmark$ & & \\
Michelson [13] & $\checkmark$ & & \\
Bellemare and Novak [14] & $\checkmark$ & $\checkmark$ & \\
Niu et al. [17] & & $\checkmark$ & \\
Huh et al. [4] & & $\checkmark$ & \\
Federgruen et al. [18] & & $\checkmark$ & $\checkmark$ \\
Our study & & & \\
\hline
\end{tabular}

2015, approximately $\$ 96$ billion was lost as a result of declines in crop and livestock production in developing countries following natural disasters. Among which, \$29 billion losses were caused by drought, which recently has battered farmers in all corners of the globe. Other meteorological disasters, such as extreme temperatures and storms, caused a loss with a price tag of $\$ 26.5$ billion [10]. More examples are witnessed during recent years. In 2016, heavy rain, storm, and hail caused wheat lodging of 2000,000 acres in Jiangsu Province in China, and the yield of the wheat dropped immensely. At the beginning of 2018, frost-damaged fruits and vegetables of 12 provinces in China, leading sharp yield decline. Under these situations, farmers may sell products outside the contract if the price on the spot market is higher than that prescribed in the contract. It has been reported that in 2020, Ukraine encountered a dry spring and summer. The drought caused yield decline and price inflation of some crops such as corns and sunflower seeds, making many farmers renege on the agricultural contracts. In this case, weather risk affects the efficiency of contract farming significantly.

Since contract farming is usually launched by firms, the core of the matter is how firms set the tactical details of the contracts under weather risk. For example, under the yield uncertainty caused by weather risk, how many farmers should the firm contract with? What is the optimal contract price? How the behaviour of farmers (renege or not), which depends on the weather condition, affects the optimal decisions and profit of the firm? And how can the firm respond to farmers' reneging?

To answer these questions, we analyse the following model and develop effective solutions: an agricultural manufacturer ("she") takes a farm crop as raw material and transforms it into a finished product (e.g., food). The demand for the product depends on the retail price. Due to the stochastic supply and price of the spot market, the manufacturer encourages local farmers ("he") to grow the farm crop by offering contracts. With these contracts, both parties agree that the harvested crop will be sold at an agreed-upon price, which we refer to as the contract price. In our model, the manufacturer determines the contract price and the number of farmers to whom she offers the contract. A farmer who accepts the contract plants the crop and promises to sell the entire harvest to the manufacturer; otherwise, he plants and sells crops at the spot market. After the weather condition and the yield are realized, farmers who have accepted the contract decide whether to honour or renege on the contract, depending on the contract price and the spot price. The manufacturer then decides the production quantity of the final product to achieve the maximal profit, according to the behaviour/decision of farmers. In this model, we allow that the manufacturer has an option to provide a counteroffer (with a new price) to any farmer who reneges on the contract.

We develop a multistage game between the profitmaximizing manufacturer and multiple identical upstream farmers under weather risk. Optimal decisions of the manufacturer are analysed with backwards induction. In addition, we numerically analyse the sensitivity of the results to model parameters, such as weather conditions and transaction costs. Contributions of this study are twofold. First, to our knowledge, this is the first study to propose a decision model that a manufacturer contracts with farmers considering the reneging behaviour of farmers under weather risk. Second, the results provide guidelines for the manufacturer to cope with farmers' reneging behaviour caused by weather risk.

The remainder of this study is organized as follows. In Section 2, we review the relevant literature. Section 3 details the description of the problem and presents the multistage model under weather risk. Section 4 provides a structural analysis exploring analytical results for the manufacturer in different stages. Section 5 presents numerical examples. Section 6 summarizes results and managerial insights. Conclusions and future research are presented in Section 7. Finally, proofs of all propositions are stated in Appendix.

\section{Literature Review}

Our work is related to three different streams of literature: contract farming, production planning under supply uncertainty, and supply chain contracts under disruption.

There is rich literature investigating contract farming, focusing on influence factors $[11,12]$ and welfare effect $[13,14]$ of contract farming, with empirical or case study. Readers can refer to Wang et al. [3], Ton et al. [15], and Bellemare and Bloem [16] for comprehensive reviews. There are a limited number of literature using analytic models to explore contract farming. Niu et al. [17] assess wholesale price contracts, cost-sharing contracts, and two cooperative's commission contracts under two-channel structures of contract farming, respectively (firm-farmer structure and firm-cooperative-farmer structure). Huh et al. [4] address contract farming by a single location manufacturer who has access to a pool of identical local farmers. Federgruen et al. [18] study a joint farmer selection and crop distribution problem for a single manufacturer who owns several manufacturing plants, each with a random demand for the crop. Niu et al. [17], Huh et al. [4], and Federgruen et al. [18] all study the contract farming problem analytically, but they do not consider the weather risk. Our study focuses on the optimal decisions of contract farming under weather risk. The differences between our study and the literature are summarized in Table 1. 
The second body is the literature on production planning under uncertain supply. Yano and Lee [19] review studies that have considered the lot-sizing problem with uncertain yield. Aslani et al. [20] present an economic order quantity (EOQ) inventory model with partial back-ordering from a supplier under yield uncertainty. They also examine two ways to improve the yield with one way to improve the mean of the yield and the other way to reduce the yield variability. Jones et al. [21] consider a two-period optimization of hybrid seed corn production when yields and demands are both random. Kazaz [22], and Kazaz and Webster [23] investigate a two-period optimization problem of the olive oil industry with farm leasing decision in the first period and olive production quantity or price decision in the second period. These two studies both consider the yield-dependent purchasing cost of the olive. Tan and Çömden [24] provide a planning methodology to determine the farm areas and seeding times for a firm that contracts with farmers located in different regions under random supply and demand. Kazaz and Webster [25] analyse the impact of supply uncertainty and risk aversion on the classic price-setting newsvendor problem. Huh and Lall [26] study the problem of land and irrigation allocation of a farmer facing rainfall and price uncertainty. Golmohammadi and Hassini [27] consider joint lot-sizing and pricing problems faced by a farmer under yield uncertainty. All these researches investigate the optimal decision of the firm or the farmer separately. There is no interaction between the firm and farms. In our study, the manufacturer's decision and farmers' decision interact with each other. Table 2 shows the difference between our model and those in the literature.

The third group of the literature investigates supply chain contracts to cope with disruptions. Sun [28] proposes a two-part tariff contract for a one-supplier-one-retailer fresh agricultural product supply chain that experiences supply disruptions during the planning horizon. Cao et al. [29] investigate a revenue-sharing contract for a supply chain investigate a revenue-sharing contract for a supply chain consisting of one manufacturer and multiple Betrand competing retailers under demand and cost disruption. The results demonstrate that the coordination scheme designed for the initial production plan should be revised when disruptions occur. Heydari et al. [30] investigate a quantity flexibility contract for a two-echelon supply chain under stochastic demand, and the results indicate that the opportunity of the manufacturer to reserve/outsource a fraction of production benefits both supply chain members under demand uncertainty. Chen et al. [31] propose and compare two incentive contracts to motivate the supplier to invest in capacity restoration for supply security. Difrancesco et al. [32] investigate two contract mechanisms, namely, risks sharing contract and buyback contract, under stochastic demand, supply uncertainty, and disruption risks. Aslani and Heydari [33] and Heydari et al. [34] both investigate the coordination mechanisms for dual-channel supply chains under channel disruptions. Aslani and Heydari [33] propose a transhipment contract to coordinate a green dual-channel supply chain under channel disruption,
TABle 2: Our study vs. the literature.

\begin{tabular}{|c|c|c|c|}
\hline \multirow{2}{*}{ Authors } & \multicolumn{3}{|c|}{ Decision-makers } \\
\hline & Firm & Farmer & Firm + farmer \\
\hline Aslani et al. [20] & $\checkmark$ & & \\
\hline Jones et al. [21] & $\checkmark$ & & \\
\hline Kazaz [22] & $\checkmark$ & & \\
\hline Kazaz and Webster [23] & $\checkmark$ & & \\
\hline Tan and Çömden [24] & $\checkmark$ & & \\
\hline Kazaz and Webster [25] & $\checkmark$ & & \\
\hline Huh and Lall [26] & & $\checkmark$ & \\
\hline Golmohammadi and Hassini [27] & & $\checkmark$ & \\
\hline Our study & & & $\checkmark$ \\
\hline
\end{tabular}

and the results illustrate that the proposed contract is capable of coordinating the supply chain and also guaranteeing the members' profitability. Heydari et al. [34] develop a collaboration mechanism based on the dominancy power of channel members to achieve coordination for a supply chain with two channels, one is the traditional retailing channel and the other is an e-channel. Four different channel disruption scenarios are considered, and a win-win solution is guaranteed for all channel members.

Especially, there is some research focusing on supply chain management under disruptions caused by weather risk and proposing some weather-linked strategies. Chen and Yano [35] and Gao et al. [36] examine a weather-linked rebate for a seasonal product whose demand is weather sensitive, but they have completely different problem scenarios: in Chen and Yano [35], the manufacturer offers a rebate to the retailer and hence improves the overall supply chain performance by sharing the weather risk; in Gao et al. [36], the weather-conditional rebate is offered to the end customers by the retailer to induce early purchases and result in cost advantages. Based on the work of Gao et al. [36], Demirag [37] further examines the risk preference of the retailer on the effectiveness of weather-linked rebate to hedge the weather risk. Gao et al. [38] study the joint decision of order quantity and option usage to hedge the inventory risk for a seasonal product whose demand is sensitive to weather conditions. Although these works focus on the scenarios that the demand is influenced by weather conditions and is different with the situation that the supply is weather-conditioned which we are interested in (see Table 3), they provide us some inspiration to investigate the impact of weather risk.

\section{The Model}

In this section, we develop a multistage game between a profit-maximizing agricultural manufacturer and multiple identical upstream farmers under weather risk. In our model, the manufacturer offers a contract to farmers, and the farmer may choose to honour or renege on the contract upon the spot price after harvest. Based on the given contract and whether the farmer honours or reneges, the manufacturer decides the production quantity of the final product to be sold in the market. 
TABLe 3: Our study vs. the literature.

\begin{tabular}{|c|c|c|c|}
\hline \multirow{3}{*}{ Authors } & \multicolumn{3}{|c|}{ Disruption risks } \\
\hline & \multicolumn{2}{|c|}{ Weather-related } & \multirow{2}{*}{ Others } \\
\hline & Demand-side & Supply-side & \\
\hline Sun $[28]$ & & & $\checkmark$ \\
\hline Cao et al. [29] & & & $\checkmark$ \\
\hline Heydari et al. [30] & & & $\checkmark$ \\
\hline Chen et al. [31] & & & $\checkmark$ \\
\hline Difrancesco et al. [32] & & & $\checkmark$ \\
\hline Aslani and Heydari [33] & & & $\checkmark$ \\
\hline Heydari et al. [34] & & & $\checkmark$ \\
\hline Chen and Yano [35] & $\checkmark$ & & \\
\hline Gao et al. [36] & $\checkmark$ & & \\
\hline Demirag [37] & $\checkmark$ & & \\
\hline Gao et al. [38] & $\checkmark$ & & \\
\hline Our study & & $\checkmark$ & \\
\hline
\end{tabular}

3.1. Manufacturer. The agricultural manufacturer takes farm crop (e.g., wheat) as raw material and transforms it into the final product (e.g., flour). The demand of the manufacturer depends on her price, and the inverse demand function is $p_{m}=a-b q_{m}$, where $a(>0)$ is the scale of the market, and $b(>0)$ is the price elasticity of the product, and $q_{m}(\geq 0)$ denotes the quantity of the final product.

There are two potential sources of the raw material for the manufacturer: the farmer and the spot market. The manufacturer may offer a contract with price $p_{c}$ to $q_{c}$ farmers, which is widely used in developing countries such as China. If the farmer reneges on the contract after harvest, the manufacturer may provide a counteroffer to renegotiate with the farmer. If the manufacturer fails to procure enough raw material, she can turn to the spot market and procures at the yield-dependent price $p_{s}$ with the unit transaction cost $c_{m}$.

3.2. Farmer. Farmers produce crops and sell to the manufacturer or the spot market. In our model, we suppose that all farmers are identical, and each of them possesses a unit area of land for simplicity. A farmer who has accepted the contract may choose to honour or renege after the yield of the crop and the spot price are realized. The phenomenon of reneging is common in developing countries as the legal systems are less effective, and farmers are too myopic to appreciate the benefit of the long-term relationship with the manufacturer. In contrast, the manufacturer does not have the flexibility to renege, since reneging is costly in terms of tarnishing her brand reputation and risking adverse political repercussions [4]. If the farmer sells his crop at the spot market, he needs to take the unit transaction cost $c_{f}$ (e.g., brokerage fee and transportation cost).

3.3. Weather Risk. The output of the farmer is affected by the weather [7-9], and it has been proved that crop growth needs a suitable weather condition, otherwise the crop yield will drop sharply [39, 40]. Without loss of generality, we consider two weather conditions: the suitable weather condition $(w=1)$ with probability $\theta$ and the unsuitable weather condition $(w=0)$ with probability $1-\theta$.

Table 4 summarizes the notation.

3.4. Sequence of Events and Model. We present the sequence of events as follows:

Stage 1: the manufacturer decides the contract price $p_{c}$ and the number of farmers $q_{c}$ to whom the contract is offered.

Stage 2: farmers who have accepted the contract harvest the crop and yield $y$ is realized. Each farmer gains $y(w)=\bar{y}$ units of the crop if the weather condition is suitable $(w=1)$ and $y(w)=y$ units otherwise $(w=0)$. The spot price $p_{s}$ is supposed to decrease in the yield $y(w)$ [23]. Farmers decide whether to honour or to renege on the contract. If farmers honour the contract, the manufacturer procures $q_{c} y(w)$ units of the crop from the contracted farmers at price $p_{c}$ per unit. Let $x$ denote the total amount of the crop, and the manufacturer procures from contracted farmers. Clearly, $x \leq q_{c} y(w)$

Stage 3: the manufacturer decides the production quantity $q_{m}$ of the final product. For simplicity, we assume that one unit of the crop is needed to produce one unit of the final product, and the unit production cost is $c_{p}$. To any farmer who has reneged on the contract, the manufacturer has an option of making a counteroffer (with a new price). The remaining shortage quantity of the crop, if any, can be procured from the spot market at price $p_{s}(y(w))$ with the unit transaction cost $c_{m}$.

Stage 4: the manufacturer sells her final product in the market at price $p_{m}$, where $p_{m}=a-b q_{m}$.

We now establish the model in a backward manner starting from stage 4 to stage 1 . Since stage 4 does not involve any decision, we only investigate the decisions in stage 1 to stage 3 .

In stage 3 , the manufacturer decides the production quantity $q_{m}$ for the final product to maximize its profit. The manufacturer's decision and profit depend on the total amount of the crop the manufacturer procures from contracted farmers $(x)$, which further depends on the farmers' decision of honouring or reneging on the contract. In the case that farmers honour the contract $\left(x=q_{c} y(w)\right)$, if $q_{m}>q_{c} y(w)$, the manufacturer will supplement the shortage $q_{m}-q_{c} y(w)$ from the sport market with unit cost $p_{s}(y(w))+c_{m}$; otherwise, the manufacturer salvages the redundant crops $q_{c} y(w)-q_{m}$ with unit revenue $h$. If farmers renege $(x=0)$, the manufacturer has an option to make a counteroffer with a new price which is at least $p_{s}(y(w))-c_{f}$ to make it be acceptable by the farmer. If $q_{m}>q_{c} y(w)$, the manufacturer will offer counteroffers to all reneged farmers and supplement the shortage $q_{m}-q_{c} y(w)$ from the sport market with unit cost $p_{s}(y(w))+c_{m}$; otherwise, the manufacturer offers counteroffers to only $q_{m} / y(w)$ number of reneged farmers. Therefore, the profit of the manufacturer is 
TABLE 4: List of notation.

\begin{tabular}{|c|c|}
\hline Notation & Definition \\
\hline 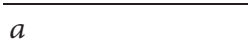 & The scale of the final product market \\
\hline$b$ & The price elasticity of the final product \\
\hline$w$ & The weather condition with $w=1$ denoting suitable weather and $w=0$ denoting unsuitable weather \\
\hline$\theta$ & The probability of suitable weather condition \\
\hline$y$ & The yield of the crop per unit area \\
\hline$c_{m}$ & Manufacturer's unit transaction cost on the spot market \\
\hline$c_{f}$ & Farmer's unit transaction cost on the spot market \\
\hline$c_{p}$ & Unit production cost of the final product \\
\hline$h^{P}$ & Salvage of unit crop \\
\hline$x$ & The total amount of the crop the manufacturer procures from contracted farmers \\
\hline$p_{m}$ & The price of the final product \\
\hline$p_{s}$ & The price of the crop on the spot market \\
\hline$p_{c}$ & The contract price \\
\hline$p_{c}^{N R}$ & The optimal contract price in Case 1 \\
\hline$p_{c}^{R}$ & The optimal contract price in Case 2 \\
\hline$q_{m}$ & The production quantity of the final product \\
\hline$q_{m}^{N R}$ & The optimal production quantity of the final product in Case 1 \\
\hline$q_{m}^{R}$ & The optimal production quantity of the final product in Case 2 \\
\hline$q_{c}$ & The number of farmers to offer contract \\
\hline$q_{c}^{N R}$ & The optimal number of farmers to offer contract in Case 1 \\
\hline$q_{c}^{R}$ & The optimal number of farmers to offer contract in Case 2 \\
\hline$\Pi\left(q_{m} \mid p_{c}, q_{c}, y(w)\right)$ & The profit of the manufacturer in stage 3 \\
\hline$P A\left(p_{c}, q_{c}, y(w)\right)$ & The maximal profit of the manufacturer in stage 3 \\
\hline$E\left(\Pi\left(p_{c}, q_{c}\right)\right)$ & The expected profit of the manufacturer in state 1 \\
\hline$E\left(\Pi\left(p_{c}^{N R}, q_{c}^{N R}\right)\right)$ & The expected profit of the manufacturer in state 1 in Case 1 \\
\hline$E\left(\Pi\left(p_{c}^{R}, q_{c}^{R}\right)\right)$ & The expected profit of the manufacturer in state 1 in Case 2 \\
\hline$\Delta \Pi \%$ & The "percentage profit gain," which is the benefits of contract farming against purchasing all crops from the spot market \\
\hline$E\left(\Pi^{N}\right)$ & The expected profit of the manufacturer without using contract farming and purchases all crops from the spot market \\
\hline$\Delta y \%$ & The impact intensity of the unsuitable weather \\
\hline
\end{tabular}

$$
\begin{aligned}
\Pi\left(q_{m} \mid p_{c}, q_{c}, y(w)\right)= & -p_{c} x-\left(p_{s}(y(w))-c_{f}\right)\left(\min \left\{q_{m}, q_{c} y(w)\right\}-x\right)^{+} \\
& -\left(p_{s}(y(w))+c_{m}\right)\left(q_{m}-q_{c} y(w)\right)^{+}+h\left(x-q_{m}\right)^{+}-c_{p} q_{m}+\left(a-b q_{m}\right) q_{m} .
\end{aligned}
$$

The first term $p_{c} x$ is the purchasing cost from the contracted farmers who honour the contract, the second term $\left(p_{s}(y(w))-c_{f}\right)\left(\min \left\{q_{m}, q_{c} y(w)\right\}-x\right)^{+}$is the purchasing cost from the farmers by counteroffers, and the third term $\left(p_{s}(y(w))+c_{m}\right)\left(q_{m}-q_{c} y(w)\right)^{+}$denotes the purchasing cost from the spot market. The fourth term $h\left(x-q_{m}\right)^{+}$ represents the salvage revenue obtained from leftover crops, and the fifth term $c_{p} q_{m}$ is the processing cost of $q_{m}$ units of final product. The final term $\left(a-b q_{m}\right) q_{m}$ is the revenue from selling $q_{m}$ units of final product in the market. The optimization problem of the manufacturer in stage 4 can be expressed as

$$
\begin{aligned}
& P A\left(p_{c}, q_{c}, y(w)\right)=\max _{q_{m}} \Pi\left(q_{m} \mid p_{c}, q_{c}, y(w)\right), \\
& \text { s.t. } q_{m} \geq 0
\end{aligned}
$$

where $p_{c}$ and $q_{c}$ are decided in stage $1, y(w)$ is realized in stage 2 , and $x$ is decided in stage 2 .

In stage 2, the farmer decides whether to honour the contract or renege on it. If he honours the contract, he will receive $p_{c}$ per unit from the manufacturer. If he reneges on the contract, he will get a unit net revenue of $p_{s}(y(w))-c_{f}$ regardless of he sells the crop to the spot market or accepts the counteroffer from the manufacturer. Thus, it is optimal for the farmer to honour the contract if $p_{s}(y(w)) \leq p_{c}+c_{f}$ and renege on it otherwise. As a result, the amount of the crop the manufacturer procures from contracted farmers at the end of stage 2 is

$$
x= \begin{cases}q_{c} y(w), & \text { if } p_{s}(y(w)) \leq p_{c}+c_{f}, \\ 0, & \text { otherwise }\end{cases}
$$

In stage 1 , the manufacturer decides the contract price $p_{c}$ and the number of farmers $q_{c}$ to whom the contract is offered. As a precondition of contract farming, the manufacturer should set a price that makes the contract acceptable. For each farmer, the expected revenue given that he signs the contract is $E_{w}\left(\max \left\{p_{c}, p_{s}(y(w))-c_{f}\right\} y(w)\right)$, which is increasing in the contract price $p_{c}$. The expected revenue of the farmer from not signing the contract and selling crops at the spot market is $E_{w}\left(\left(p_{s}(y(w))-c_{f}\right) y(w)\right)$. Since $E_{w}\left(\max \left\{p_{c}, p_{s}(y(w))-c_{f}\right\} y(w)\right)$ is always larger than $E_{w}\left(\left(p_{s}(y(w))-c_{f}\right) y(w)\right)$, the farmer will always accept the contract. Therefore, we can get the optimal contract price $p_{c}$ and amount of the contracts $q_{c}$ by solving the following optimization problem. 


$$
\begin{aligned}
& \max _{p_{c}, q_{c}} E\left(\Pi\left(p_{c}, q_{c}\right)\right)=E_{w}\left(P A\left(p_{c}, q_{c}, y(w)\right)\right), \\
& \text { s.t. } q_{c} \geq 0 .
\end{aligned}
$$

\section{The Analysis}

The purpose of this section is to derive the optimal decisions for the manufacturer considering the behaviour of the farmer. We need to analyse different cases of whether farmers renege on the contract considering weather conditions. There are four different cases.

Case 1: farmers honour the contract under both weather conditions, that is, $p_{s}(\bar{y})-c_{f} \leq p_{c}, p_{s}(y)-c_{f} \leq p_{c}$;

Case 2: farmers honour the contract under suitable weather but renege under unsuitable weather, that is, $p_{s}(\bar{y})-c_{f} \leq p_{c}, p_{s}(\underline{y})-c_{f}>p_{c}$;

Case 3: farmers honour the contract under unsuitable weather but renege under suitable weather, i.e., $p_{s}(\bar{y})-c_{f}>p_{c}, p_{s}(\underline{y})-c_{f} \leq p_{c}$;
Case 4: farmers renege on the contract under both weather conditions, $p_{s}(\bar{y})-c_{f}>p_{c}, p_{s}(\underline{y})-c_{f}>p_{c}$.

Note that $p_{s}(y)$ decreases in $y$; therefore, Case 3 is impossible. Moreover, Case 4 is meaningless to the manufacturer. Therefore, we only discuss Case 1 and Case 2.

Case 1. Farmers Honour the Contract under both Weather Conditions

In this case, the manufacturer should set a contract price no less than $\max \left\{p_{s}(\bar{y})-c_{f}, p_{s}(y)-c_{f}\right\}$, to ensure contracted farmers to honour the contract under both weather conditions. We solve the model in Case 1 with a backward manner. Note that $x=q_{c} y(w)$ under both suitable and unsuitable weather conditions in this case.

Proposition 1. In Case 1, for any realized yield $y(w)$ and the decision $p_{c}$ and $q_{c}$, the profit of the manufacturer $\Pi\left(q_{m} \mid p_{c}, q_{c}, y(w)\right)$ (equation (1)) is concave in $q_{m}$, and the optimal production quantity $q_{m}$ is

$$
q_{m}^{N R}= \begin{cases}\frac{a-p_{s}(y(w))-c_{m}-c_{p}}{2 b}, & \text { when } q_{c} y(w) \leq \frac{a-p_{s}(y(w))-c_{m}-c_{p}}{2 b}, \\ q_{c} y(w), & \text { when } \frac{a-p_{s}(y(w))-c_{m}-c_{p}}{2 b}<q_{c} y(w) \leq \frac{a-h-c_{p}}{2 b}, \\ \frac{a-h-c_{p}}{2 b}, & \text { when } q_{c} y(w)>\frac{a-h-c_{p}}{2 b} .\end{cases}
$$

In Proposition 1, $\left(a-p_{s}(y(w))-c_{m}-c_{p}\right) / 2 b$ represents the target amount of the final product if crops from contracted farmers are not enough, and the manufacturer needs to supplement the shortage from the spot market; $\left(a-h-c_{p}\right) / 2 b$ can be considered as the target amount of the final product if there are plenty of crops from contracted farmers. If the amount of crops from contracted farmers $q_{c} y(w)$ lies between $\left(a-p_{s}(y(w))-c_{m}-c_{p}\right) / 2 b$ and $\left(a-h-c_{p}\right) / 2 b$, the optimal choice for the manufacturer is to produce the final product as much as $q_{c} y(w)$. The reason is that if she purchases additional crops from the spot market and produces the final product, the unit revenue of these extra products is not enough to offset the cost of the unit crop; if she leaves some of the crops as salvage, the salvage value of the crop cannot make up the revenue loss of producing and selling the final product.

Proposition 1 shows that $q_{m}^{N R}$ depends on the weather condition $w$, and then, we have the following corollary.

\section{Corollary 1. In Case 1,}

(a) Given the realized weather condition $w=1$ and realized yield $y(w)=\bar{y}$, and the optimal production quantity of the manufacturer is

$$
q_{m}^{N R}= \begin{cases}\frac{a-p_{s}(\bar{y})-c_{m}-c_{p}}{2 b}, & \text { when } q_{c} \bar{y} \leq \frac{a-p_{s}(\bar{y})-c_{m}-c_{p}}{2 b} \\ q_{c} \bar{y}, & \text { when } \frac{a-p_{s}(\bar{y})-c_{m}-c_{p}}{2 b}<q_{c} \bar{y} \leq \frac{a-h-c_{p}}{2 b}, \\ \frac{a-h-c_{p}}{2 b}, & \text { when } q_{c} \bar{y}>\frac{a-h-c_{p}}{2 b}\end{cases}
$$


(b) Given the realized weather condition $w=0$ and realized yield $y(w)=y$, and the optimal production quantity of the manufacturer is

$$
q_{m}^{N R}= \begin{cases}\frac{a-p_{s}(\underline{y})-c_{m}-c_{p}}{2 b}, & \text { when } q_{c} \underline{y} \leq \frac{a-p_{s}(\underline{y})-c_{m}-c_{p}}{2 b}, \\ q_{c} \underline{y}, & \text { when } \frac{a-p_{s}(\underline{y})-c_{m}-c_{p}}{2 b}<q_{c} \underline{y} \leq \frac{a-h-c_{p}}{2 b}, \\ \frac{a-h-c_{p}}{2 b}, & \text { when } q_{c} \underline{y}>\frac{a-h-c_{p}}{2 b} .\end{cases}
$$

For simplicity, we use $T A_{1}$ and $T A_{2}$ to denote $(a-h-$ $\left.c_{p}\right) / 2 b$ and $\left(a-p_{s}(y)-c_{m}-c_{p}\right) / 2 b$ separately in the following discussion.

Proposition 2. In Case 1, $E\left(\Pi\left(p_{c}, q_{c}\right)\right)$ is decreasing in $p_{c}$ and is concave in $q_{c}$. The optimal contract price is
$p_{c}^{N R}=p_{s}(y)-c_{f}$, and the optimal quantity of farmers to offer the contract is shown in Table 5.where $A=\theta \bar{y}\left(h-p_{s}(y)+c_{f}\right)+(1-\theta) y\left(c_{m}+c_{f}\right)$ is the firstorder derivation of $E\left(\Pi\left(p_{c}, q_{c}\right)\right)$ on $q_{c}$ in interval $[(a-h-$ $\left.\left.c_{p}\right) / 2 b \bar{y},\left(a-p_{s}(\underline{y})-c_{m}-c_{p}\right) / 2 b \underline{y}\right]$ in Case 1 .

$$
B=\theta \bar{y}\left(h-p_{s}(\underline{y})+c_{f}\right)+(1-\theta) \underline{\underline{y}}\left(\frac{a-p_{s}(\underline{y})+c_{f}-c_{p}}{\underline{y}}-\frac{a-h-c_{p}}{\bar{y}}\right),
$$

is the first-order derivation of $E\left(\Pi\left(p_{c}, q_{c}\right)\right)$ on $q_{c}$ at $q_{c}=$ $\left(a-p_{s}(\underline{y})-c_{m}-c_{p}\right) / 2 b \underline{y}$ in Case 1 .

$$
\begin{aligned}
C= & \theta \bar{y}^{2}\left(\frac{a-p_{s}(\underline{y})+c_{f}-c_{p}}{\bar{y}}-\frac{a-p_{s}(\underline{y})-c_{m}-c_{p}}{\underline{y}}\right) \\
& +(1-\theta) \underline{y}\left(c_{m}+c_{f}\right)
\end{aligned}
$$

is the first-order derivation of $E\left(\Pi\left(p_{c}, q_{c}\right)\right)$ on $q_{c}$ at $q_{c}=\left(a-h-c_{p}\right) / 2 b \bar{y}$ in Case 1.

Substituting $p_{c}^{N R}$ and $q_{c}^{N R}$ into equation (1), we get the maximal excepted profit of the manufacturer $E\left(\Pi\left(p_{c}^{N R}, q_{c}^{N R}\right)\right)$ in Case 1 as shown in Corollary 2.

Corollary 2. The maximal excepted profit of the manufacturer $E\left(\Pi\left(p_{c}^{N R}, q_{c}^{N R}\right)\right)$ in Case 1 is shown in Table 6.
Case 2. Farmers Honour the Contract under Suitable Weather but Renege under Unsuitable Weather

In this case, the manufacturer sets a contract price within the interval $\left[p_{s}(\bar{y})-c_{f}, p_{s}(y)-c_{f}\right)$ to guarantee farmers will not renege under suitable weather condition. If the realized weather condition is unsuitable and farmers renege, she may renegotiate with part of the reneged farmers with a higher new price. In other words, the manufacturer has an option to purchase crops from the reneged farmers if necessary. Note that, in Case 2, we have $x=q_{c} y(w)$ if the weather condition is suitable and $x=0$ otherwise.

Proposition 3. In Case 2, for any realized yield $y(w)$ and the manufacturer's decision $p_{c}$ and $q_{c}$, the profit of the manufacturer $\Pi\left(q_{m} \mid p_{c}, q_{c}, y(w)\right)$ (equation (1)) is concave in $q_{m}$, and the optimal production quantity $q_{m}$ is shown as follows:

(a) If the realized weather condition $w=1$, the optimal production quantity of the manufacturer is

$$
q_{m}^{R}= \begin{cases}\frac{a-p_{s}(\bar{y})-c_{m}-c_{p}}{2 b}, & \text { when } q_{c} \bar{y} \leq \frac{a-p_{s}(\bar{y})-c_{m}-c_{p}}{2 b}, \\ q_{c} \bar{y}, & \text { when } \frac{a-p_{s}(\bar{y})-c_{m}-c_{p}}{2 b}<q_{c} \bar{y} \leq \frac{a-h-c_{p}}{2 b}, \\ \frac{a-h-c_{p}}{2 b}, & \text { when } q_{c} \bar{y}>\frac{a-h-c_{p}}{2 b} .\end{cases}
$$


TABle 5: Optimal quantity of farmers to offer the contract in Case 1.

\begin{tabular}{lcc}
\hline Parameter scenario 1 & Parameter scenario 2 & $q_{c}^{N R}$ \\
\hline$\left(T A_{1} / \bar{y}\right) \leq\left(T A_{2} / \underline{y}\right)$ & $A>0$ & $\left(\left(\theta \bar{y}\left(h-p_{s}(y)+c_{f}\right)+(1-\theta) y\left(a-p_{s}(y)+c_{f}-c_{p}\right)\right) / 2 b(1-\theta) y^{2}\right)$ \\
& $A \leq 0$ & $\left(\theta \bar{y}\left(a-p_{s}(y)+c_{f}-c_{p}\right)+(1-\theta) y\left(c_{m}+c_{f}\right) / 2 b \theta \bar{y}^{2}\right)$ \\
$\left(T A_{1} / \bar{y}\right)>\left(T A_{2} / \underline{y}\right)$ & $B>0$ & $\left(\theta \bar{y}\left(h-p_{s}(y)+c_{f}\right)+(1-\theta) y\left(a-p_{s}(y)+c_{f}-c_{p}\right)\right) / 2 b(1-\theta) y^{2}$ \\
& $B \leq 0<C$ & $(\theta \bar{y}+(1-\theta) y)\left(a-p_{s}(y)+c_{f}-c_{p}\right) / 2 b\left(\theta \bar{y}^{2}+(1-\theta) y^{2}\right)$ \\
& $C \leq 0$ & $\left(\theta \bar{y}\left(a-p_{s}(y)+c_{f}-\bar{c}_{p}\right)+(1-\theta) y\left(c_{m}+c_{f}\right)\right) / 2 b \theta \bar{y}^{2}$ \\
\hline
\end{tabular}

TABLE 6: The maximal excepted profit of the manufacturer in Case 1.

\begin{tabular}{lcc}
\hline $\begin{array}{l}\text { Parameter scenario } \\
1\end{array}$ & $\begin{array}{c}\text { Parameter } \\
\text { scenario } 2\end{array}$ & $E\left(\Pi\left(p_{c}^{N R}, q_{c}^{N R}\right)\right)$ \\
\hline$\left(T A_{1} / \bar{y}\right) \leq\left(T A_{2} / \underline{y}\right)$ & $A>0$ & $\left(\left(\theta \bar{y}\left(h-p_{s}(\underline{y})+c_{f}\right)+(1-\theta) \underline{y}\left(a-p_{s}(\underline{y})+c_{f}-c_{p}\right)\right)^{2}+\theta(1-\theta) \underline{\left.y^{2}\left(a-h-c_{p}\right)^{2}\right) / 4 b(1-\theta) \underline{y}^{2}}\right.$ \\
& $A \leq 0$ & $\left(\left(\theta \bar{y}\left(a-p_{s}(\underline{y})+c_{f}-c_{p}\right)+(1-\theta) \underline{y}\left(c_{m}+c_{f}\right)\right)^{2}+\theta(1-\theta) \bar{y}^{2}\left(a-p_{s}(\underline{y})-c_{m}-c_{p}\right)^{2}\right) / 4 b \theta \bar{y}^{2}$ \\
$\left(T A_{1} / \bar{y}\right)>\left(T A_{2} / \underline{y}\right)$ & $B>0$ & $\left(\left(\theta \bar{y}\left(h-p_{s}(\underline{y})+c_{f}\right)+(1-\theta) \underline{y}\left(a-p_{s}(\underline{y})+c_{f}-c_{p}\right)\right)^{2}+\theta(1-\theta) \underline{y}^{2}\left(a-h-c_{p}\right)^{2}\right) / 4 b(1-\theta) \underline{y}^{2}$ \\
& $B \leq 0<C$ & $(\theta \bar{y}+(1-\theta) \underline{y})^{2}\left(a-p_{s}(\underline{y})+c_{f}-c_{p}\right)^{2} / 4 b\left(\theta \bar{y}^{2}+(1-\theta) \underline{y}^{2}\right)$ \\
& $C \leq 0$ & $\left(\left(\theta \bar{y}\left(a-p_{s}(\underline{y})+c_{f}-c_{p}\right)+(1-\theta) \underline{y}\left(c_{m}+c_{f}\right)\right)^{2}+\theta(1-\theta) \bar{y}^{2}\left(a-p_{s}(\underline{y})-c_{m}-c_{p}\right)^{2}\right) / 4 b \theta \bar{y}^{2}$ \\
\hline
\end{tabular}

(b) If the realized weather condition $w=0$, the optimal production quantity of the manufacturer is

$$
q_{m}^{R}= \begin{cases}\frac{a-p_{s}(\underline{y})-c_{m}-c_{p}}{2 b}, & \text { when } q_{c} \underline{y} \leq \frac{a-p_{s}(\underline{y})-c_{m}-c_{p}}{2 b}, \\ q_{c} \underline{y}, & \text { when } \frac{a-p_{s}(\underline{y})-c_{m}-c_{p}}{2 b}<q_{c} \underline{y} \leq \frac{a-p_{s}(\underline{y})+c_{f}-c_{p}}{2 b}, \\ \frac{a-p_{s}(\underline{y})+c_{f}-c_{p}}{2 b}, & \text { when } q_{c} \underline{y}>\frac{a-p_{s}(\underline{y})+c_{f}-c_{p}}{2 b} .\end{cases}
$$

Here, $\left(a-p_{s}(y)+c_{f}-c_{p}\right) / 2 b$ represents the target amount of the final product when the yield is low due to unsuitable weather, and the manufacturer and the farmer agree on a new counteroffer price $p_{s}(y)-c_{f}$. We use $T A_{3}$ to denote it in the following. Proposition 3 shows that if the total amount of crops of contracted farmers is too small, the manufacturer always needs to supplement crops from the spot market up to $\left(a-p_{s}(y(w))-c_{m}-c_{p}\right) / 2 b$, no matter farmers renege or not. However, if the total amount of crops of contracted farmers is large enough, the manufacturer has to treat crops more than $\left(a-h-c_{p}\right) / 2 b$ as residuals in the situation that farmers do not renege under suitable weather, or to make a counteroffer to some farmers to get as many as $\left(a-p_{s}(y)+c_{f}-c_{p}\right) / 2 b$ crops in the situation that farmers renege under unsuitable weather.

Proposition 4. In Case 2, $E\left(\Pi\left(p_{c}, q_{c}\right)\right)$ is decreasing in $p_{c}$ and is concave in $q_{c}$. The optimal contract price is $p_{c}^{R}=p_{s}(\bar{y})-c_{f}$, and the optimal quantity of farmers to offer the contract is shown in Table 7. where $D=\theta \bar{y}\left(h-p_{s}(\bar{y})+\right.$ $\left.c_{f}\right)+(1-\theta) y\left(c_{m}+c_{f}\right)$ is the first-order derivation of $E\left(\Pi\left(p_{c}, q_{c}\right)\right)$ on $q_{c}$ in interval $\left[\left(a-h-c_{p}\right) / 2 b \bar{y},\left(a-p_{s}\right.\right.$ $\left.\left.(\underline{y})-c_{m}-c_{p}\right) / 2 b \underline{y}\right]$ in Case 2.

$$
E=\theta \bar{y}\left(h-p_{s}(\bar{y})+c_{f}\right)+(1-\theta)^{2} \underline{y}\left(\frac{a-p_{s}(\underline{y})+c_{f}-c_{p}}{\underline{y}}-\frac{a-h-c_{p}}{\bar{y}}\right)
$$

is the first-order derivation of $E\left(\Pi\left(p_{c}, q_{c}\right)\right)$ on $q_{c}$ at $q_{c}=\left(\left(a-p_{s}(\underline{y})-c_{m}-c_{p}\right) / 2 b \underline{y}\right)$ in Case 2. 
TABLE 7: Optimal quantity of farmers to offer the contract in Case 2.

\begin{tabular}{lcr}
\hline Parameter scenario 1 & Parameter scenario 2 & $q_{c}^{R}$ \\
\hline \multirow{2}{*}{$\left(T A_{1} / \bar{y}\right) \leq\left(T A_{2} / \underline{y}\right)$} & $D>0$ & $\left(\theta \bar{y}\left(h-p_{s}(\bar{y})+c_{f}\right)+(1-\theta) y\left(a-p_{s}(y)+c_{f}-c_{p}\right)\right) / 2 b(1-\theta) \underline{y}^{2}$ \\
& $D \leq 0$ & $\left(\theta \bar{y}\left(a-p_{s}(\bar{y})+c_{f}-c_{p}\right)+(1-\theta) \underline{y}\left(c_{f}+c_{m}\right)\right) / 2 b \theta \bar{y}^{2}$ \\
$\left(T A_{2} / \underline{y}\right)<\left(T A_{1} / \bar{y}\right) \leq\left(T A_{3} / \underline{y}\right)$ & $E \leq 0<F$ & $\left(\theta \bar{y}\left(a-p_{s}(\bar{y})+c_{f}-c_{p}\right)+(1-\theta) y\left(a-p_{s}(y)+c_{f}-c_{p}\right)\right) / 2 b\left(\theta \bar{y}^{2}+(1-\theta) \underline{y}^{2}\right)$ \\
& $F \leq 0$ & $\left(\theta \bar{y}\left(a-p_{s}(\bar{y})+c_{f}-\bar{c}_{p}\right)+(1-\bar{\theta}) \underline{y}\left(c_{f}+c_{m}\right)\right) / 2 b \theta \bar{y}^{2}$ \\
$\left(T A_{1} / \bar{y}\right)>\left(T A_{3} / \underline{y}\right)$ & $F>0$ & $\left(\theta \bar{y}\left(a-p_{s}(\bar{y})+c_{f}-c_{p}\right)+(1-\theta) y\left(a-p_{s}(y)+c_{f}-c_{p}\right)\right) / 2 b\left(\theta \bar{y}^{2}+(1-\theta) \underline{y}^{2}\right)$ \\
& $F \leq 0$ & $\left(\theta \bar{y}\left(a-p_{s}(\bar{y})+c_{f}-\bar{c}_{p}\right)+(1-\bar{\theta}) y\left(c_{f}+c_{m}\right)\right) / 2 b \theta \bar{y}^{2}$ \\
\hline
\end{tabular}

$$
\begin{aligned}
F= & \theta \bar{y}^{2}\left(\frac{a-p_{s}(\bar{y})+c_{f}-c_{p}}{\bar{y}}-\frac{a-p_{s}(\underline{y})-c_{m}-c_{p}}{\underline{y}}\right) \\
& +(1-\theta) \underline{y}\left(c_{m}+c_{f}\right),
\end{aligned}
$$

is the first-order derivation of $E\left(\Pi\left(p_{c}, q_{c}\right)\right)$ on $q_{c}$ at $q_{c}=$ $\left(a-h-c_{p}\right) / 2 b \bar{y}$ in Case 2.

Substituting $p_{c}^{R}$ and $q_{c}^{R}$ into equation (1), we get the maximal excepted profit of the manufacturer $E\left(\Pi\left(p_{c}^{R}, q_{c}^{R}\right)\right)$ in Case 2 as shown in Corollary 3.

Corollary 3. The maximal excepted profit of the manufacturer $E\left(\Pi\left(p_{c}^{R}, q_{c}^{R}\right)\right)$ in Case 2 is shown in Table 8.

Thus far, we have analysed the optimal decisions and the profits of the manufacturer in all possible cases, considering the reneging behaviour of the farmer. We now compare these two cases, focusing on the optimal decisions and the expected profit of the manufacturer, and then give guidelines for the optimal decisions of the manufacturer. The results are shown in Proposition 5.

$$
\begin{aligned}
& \text { Proposition 5. (a) } \quad p_{c}^{N R}>p_{c}^{R} . \quad \text { (b) } q_{c}^{N R}<q_{c}^{R} . \\
& E\left(\Pi\left(p_{c}^{N R}, q_{c}^{N R}\right)\right)<E\left(\Pi\left(p_{c}^{R}, q_{c}^{R}\right)\right) .
\end{aligned}
$$

It is shown in Proposition 5(a) that the manufacturer should offer a higher contract price in Case 1 to guarantee that the farmers will not renege under both weather conditions. Proposition 5(b) indicates that the manufacturer offers the contract to fewer farmers in Case 1. This may be because that the manufacturer needs to accept all the crops from these contracted farmers in Case 1, and if the number of contracted farmers is large, the manufacturer may suffer the loss due to salvage. Proposition 5(c) shows that the manufacturer can get a higher expected profit in Case 2, and there is no need to set a high contract price to prevent farmers from reneging. The underlying reason is that the manufacturer has a chance to provide a counteroffer to the reneged farmers at price $p_{s}(y)-$ $c_{f}$ which is lower than the cost $p_{s}(y)+c_{m}$ of purchasing from the spot market. In other words, the manufacturer benefits from the procurement cost difference between counteroffer and spot market. While the procurement cost difference increases, that is, $c_{f}+c_{m}$ increases, the manufacturer gains more profit.

\section{Numerical Analysis}

Our analytical results provide the optimal decisions of the manufacturer who uses contract farming to ensure crop supply under weather risk. It is valuable to generate further managerial insights on the impact of parameters such as weather risk and transaction cost on manufacturer's optimal decisions and the effectiveness of contract farming.

To check the effectiveness of contract farming to the manufacturer, we quantify the benefits of contract farming against purchasing all crops from the spot market with the "percentage profit gain", that is,

$$
\Delta \Pi \%=\frac{E\left(\Pi\left(p_{c}^{R}, q_{c}^{R}\right)\right)-E\left(\Pi^{N}\right)}{E\left(\Pi^{N}\right)} \times 100 \%,
$$

where $E\left(\Pi^{N}\right)$ is the expected profit of the manufacturer without using contract farming and purchases all crops from the spot market. Moreover, we report the influence of weather risk and transaction cost on the number of farmers to offer contract $q_{c}^{R}$ but omit the optimal contract price $p_{c}^{R}$, since it is straightforward according to Proposition 4 . For the numerical examples, we set the base case parameterized as follows: $\theta=0.5, \bar{y}=10, y=5, c_{f}=5, c_{p}=5, c_{m}=5$, $a=500, b=4, h=2$. The relationship between spot market price $p_{s}$ and yield $y$ follows $p_{s}(y)=30-2 y$. When a particular model parameter is under consideration, its values will differ from the base case and will be specified in the corresponding examples.

5.1. Impact of Weather Risk. In this study, weather risk is described by two parameters. One is the probability of unsuitable weather condition for the crop, which is denoted by $1-\theta$. As $1-\theta$ increases, the unsuitable weather condition is more likely to realize. The other is the impact intensity of the unsuitable weather condition, which is denoted by $\Delta y \%=((\bar{y}-y) / \bar{y}) \times 100 \%$. Larger $\Delta y \%$ represents a more serious impact of the unsuitable weather on the yield of the crop.

Figure 1 (a) shows that the percentage profit gain, $\Delta \Pi \%$, is always positive, indicating that contract farming is beneficial for the manufacturer. In Figure 1(b), the optimal number of farmers to offer contract increases as $1-\theta$ increases. This implies that the manufacturer should offer contracts to more farmers if the weather condition is more likely to be bad. In both Figure 1(a) and Figure 1(b), there is a "lane change" of both the percentage profit gain, $\Delta \Pi \%$, and the optimal numbers of farmers to offer contract, $q_{c}^{R}$, at some $(1-\theta)^{*}(=0.375)$. We found that $(1-\theta)^{*}$ corresponds to the condition that $D=0$. When $1-\theta$ is small (weather risk is small), $D=\theta \bar{y}\left(h-p_{c}^{R}\right)+(1-\theta) y\left(c_{f}+c_{m}\right)$ is negative; 


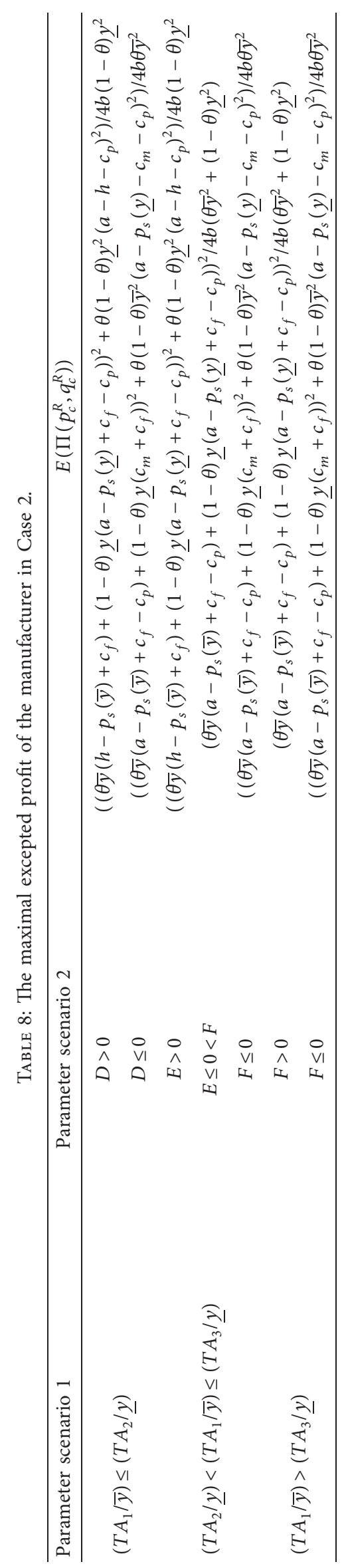




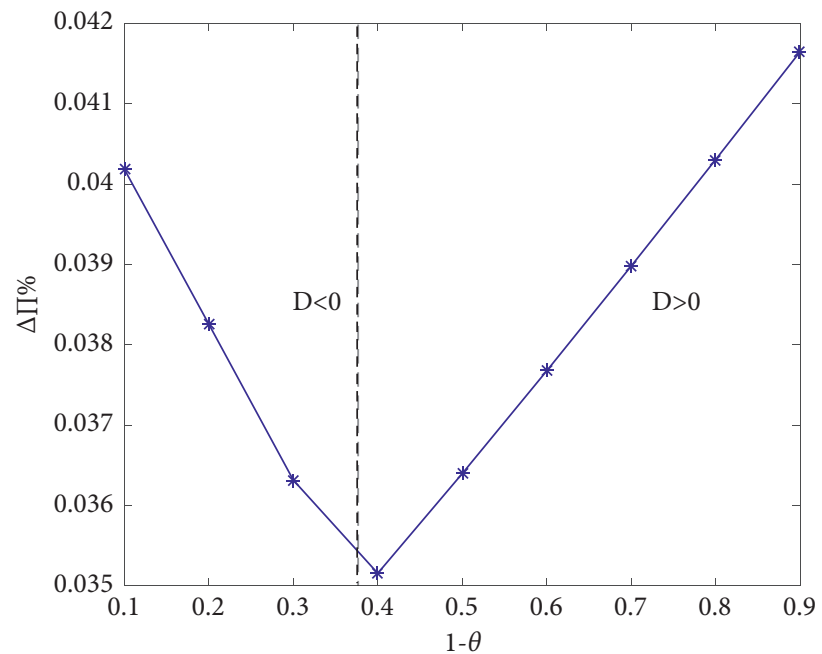

(a)

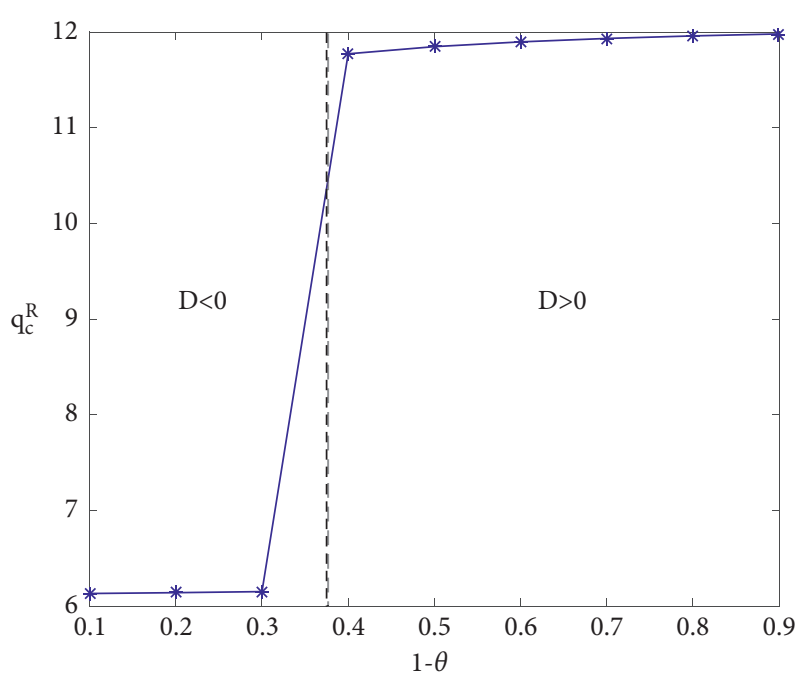

(b)

FIGURE 1: Impact of weather risk (increasing $1-\theta$ ). (a) Impact of weather risk on the percentage profit gain $\Delta \Pi \%$; (b) impact of weather risk on the number of farmers to offer contract $q_{c}^{R}$ under contract farming.

that is, the cost caused by overstock under suitable weather dominates the cost caused by understock under unsuitable weather. Therefore, the manufacturer should offer less contracts. As $1-\theta$ increases (weather risk increases), $D$ becomes positive, which means the cost caused by understock under unsuitable weather dominates the cost caused by overstock under suitable weather. In this case, the manufacturer should offer more contracts. The influence of weather risk $1-\theta$ on the percentage profit gain $\Delta \Pi \%$ is complex, and it decreases on $1-\theta$ when $1-\theta<(1-\theta)^{*}$ and increases on $1-\theta$ otherwise.

It is shown in Figure 2(a) that the percentage profit gain, $\Delta \Pi \%$, is always positive, indicating that contract farming is beneficial for the manufacturer, regardless of the impact intensity of the unsuitable weather. However, as the impact of the unsuitable weather becomes more serious $(\Delta y \%$ increases), the effectiveness of contract farming is weakened. This result further testifies that contract farming is adversely affected by the weather risk. There is also a turning point of the percentage profit gain, $\Delta \Pi \%$, and the optimal numbers to offer contract, $q_{c}^{R}$, at some $(\Delta y \%)^{*}(=0.7)$ in Figures 2(a) and $2(\mathrm{~b})$. The turning point is also decided by $D=0$. When $\Delta y \%<0.7, D$ is positive, which means that the cost caused by understock under unsuitable weather dominates the cost caused by overstock under suitable weather. Therefore, the manufacturer should offer contracts to more farmers (larger $q_{c}^{R}$ ) than that when $\Delta y \%>0.7$. And more contracts should be offered as the impact of unsuitable weather becomes more serious. When $\Delta y \%>0.7, D$ becomes negative. The manufacturer should contract with less farmers since the cost caused by overstock under suitable weather dominates the cost caused by understock under unsuitable weather. Besides, when $\Delta y \%>0.7$, as the impact of unsuitable weather becomes more serious, the manufacturer should contract with less farmers. This may be because the drastic decline in the yield of the crop causes steep rise in spot price of the crop, and the manufacturer may decrease production quantity of the final product to resist the rising cost.

5.2. Impact of Transaction Costs. We have found in Section 4 that it is the procurement cost difference $c_{f}+c_{m}$ between from the spot market and from the reneged farmers with a counteroffer which benefits the manufacturer in Case 2 . Figures 3(a) and 4(a) show that the percentage profit gain, $\Delta \Pi \%$, increases with $c_{f}$ and $c_{m}$, denoting that contract farming is more beneficial for the manufacturer when $c_{f}$ and $c_{m}$ increase. In Figure 3(b), we find that the optimal number to offer contract, $q_{c}^{R}$, increases with $c_{f}$. This is due to that the manufacturer can purchase crops from reneged farmers with a lower option price $p_{s}(y)-c_{f}$ as farmer's transaction cost, $c_{f}$, increases. In Figure $4(\mathrm{~b})$, the optimal number to offer contract, $q_{c}^{R}$, also increases with $c_{m}$. This is because that as $c_{m}$ increases, it becomes more and more expensive for the manufacturer to purchase crops from the spot market than from contracted farmers. The turning points at $(\partial E(\Pi$ $\left.\left.\left(p_{c}^{N R}, q_{c}\right)\right) / \partial q_{c}\right)=\theta \bar{y}\left(h-p_{c}^{N R}\right)+(1-\theta) \underline{y}\left(a-p_{c}^{N R}-c_{p}\right)-$ $2(1-\theta) b y^{2} q_{c}$ in Figure 3 and $c_{m}=1$ in Figure 4 are also correspond to $D=0$.

\section{Managerial Implications}

In this study, we focus on optimal decisions for contract farming under weather risk. From the analytical analysis and the numerical simulation, we can get the following results.

First, the analytical analysis of the Stackelberg model achieves that the optimal decisions of the manufacturer in Case 2 dominate those in Case 1. We discuss two different cases in this study. In Case 1, the manufacturer offers a high contract price, and farmers honour the contract under both weather conditions. In Case 2, the manufacturer sets a 


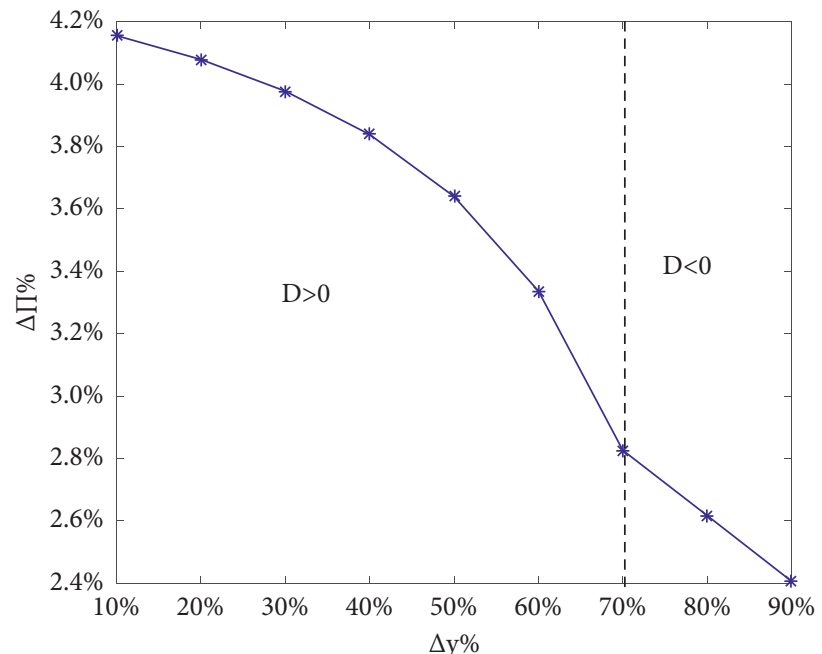

(a)

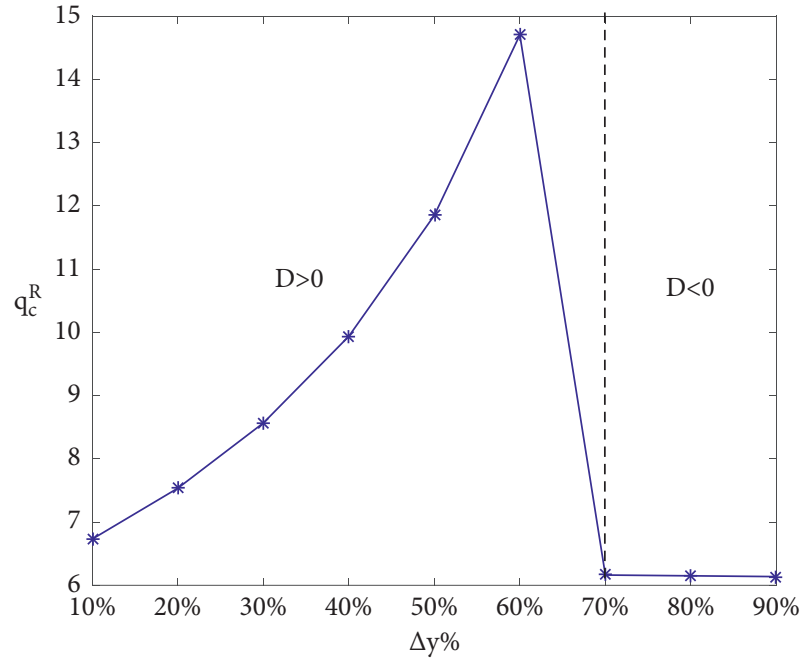

(b)

FiguRE 2: Impact of weather risk (increasing $\Delta y \%$ ). (a) Impact of weather risk on the percentage profit gain $\Delta \Pi \%$; (b) impact of weather risk on the number of farmers to offer contract $q_{c}^{R}$ under contract farming.

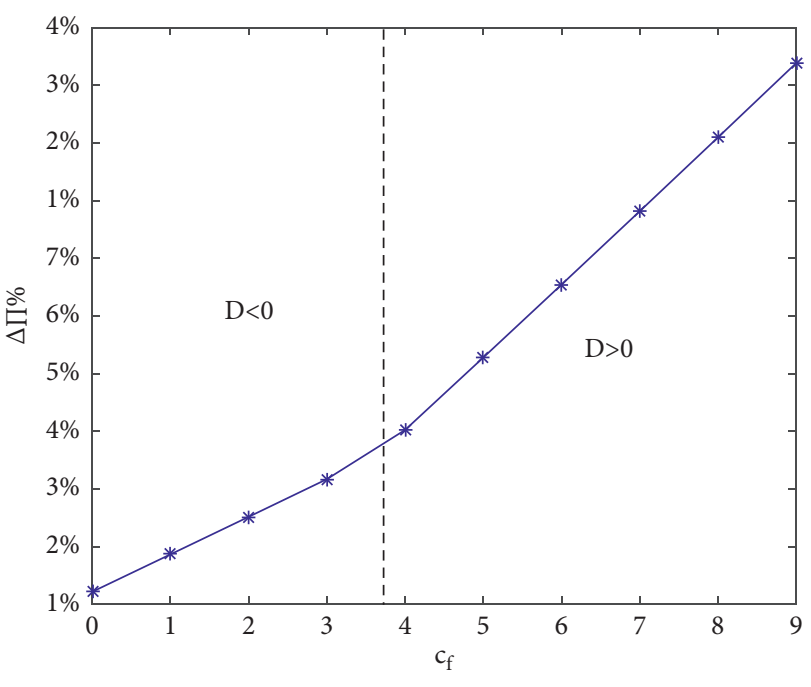

(a)

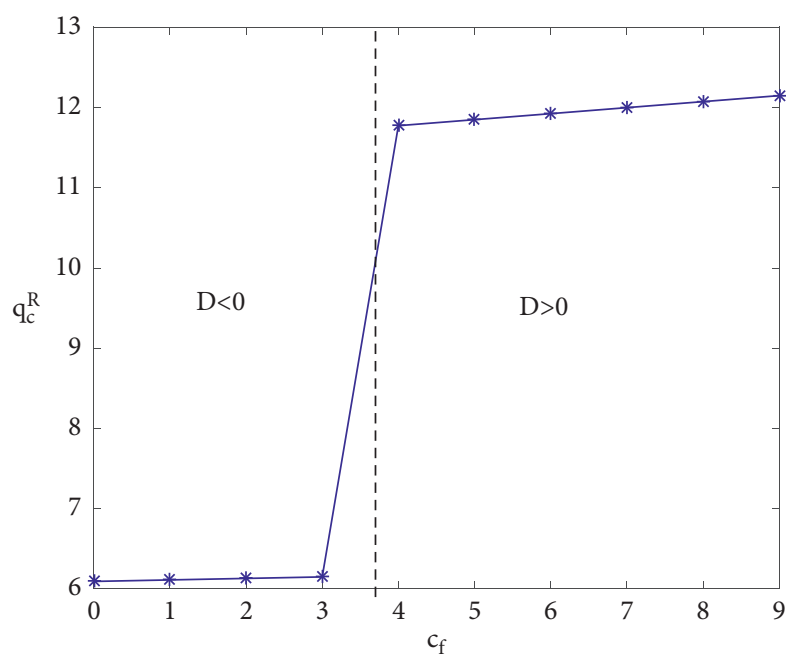

(b)

FIGURE 3: Impact of farmers' transaction cost (increasing $c_{f}$ ). (a) Impact of farmers' transaction cost on the percentage profit gain $\Delta \Pi \%$; (b) impact of farmers' transaction cost on the number of farmers to offer contract $q_{c}^{R}$ under contract farming.

relatively lower price to guarantee farmers not to renege under suitable weather condition, but if the weather condition is unsuitable and farmers renege, she has a second chance to renegotiate with part of the reneged farmers with a higher new price. In order to enable reneged farmers to accept the counteroffer, the new price should be not less than $p_{s}(\bar{y})-c_{f}$, which is the unit net profit farmers can get from the spot market. The results show that the manufacturer gains a higher profit in Case 2. Therefore, it is not necessary to set a high contract price to avoid farmers reneging. We can also conclude from the model that the profit advantage in Case 2 is due to the procurement cost difference between purchasing from reneged farmers with a counteroffer and from the spot market.
Second, the numerical analysis on impact of weather risk on the effectiveness of contract farming shows that contract farming is beneficial for the manufacturer under whichever weather condition. But the impact mechanism of the weather risk is complex. The effectiveness of contract farming, which is denoted by the percentage profit gain $\Delta \Pi \%$, first decreases and then increases on the probability of unsuitable weather condition $(1-\theta)$. But it always decreases when the impact of the unsuitable weather becomes more serious ( $\Delta y \%$ increases). Similarly, the impact of weather risk on the optimal number of farmers to offer contract $\left(q_{c}^{R}\right)$ is also complex. The results depend on the value of $D=\theta \bar{y}\left(h-p_{c}^{R}\right)+(1-\theta) y\left(c_{f}+c_{m}\right)$. Negative $D$ denotes 


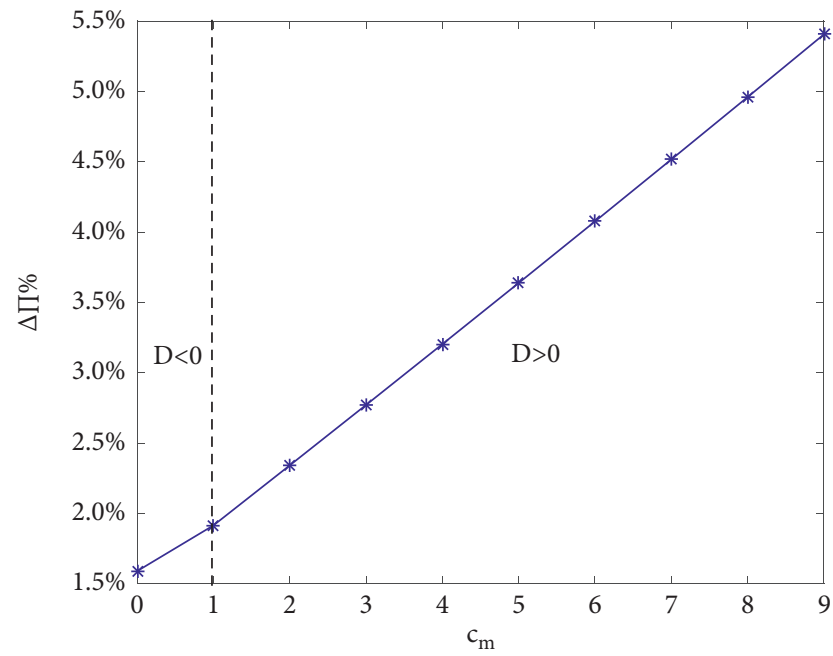

(a)

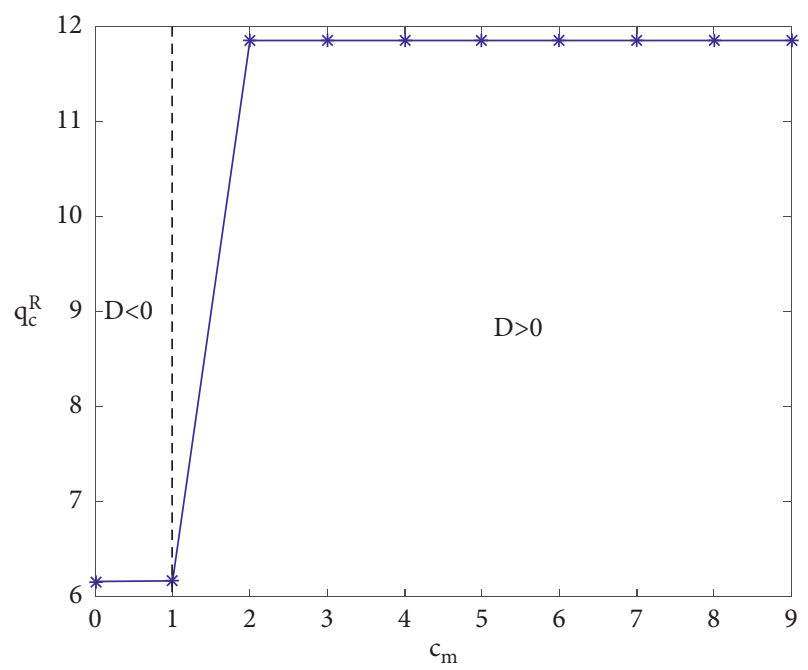

(b)

FIGURE 4: Impact of manufacturer's transaction cost (increasing $c_{m}$ ). (a) Impact of manufacturer's transaction cost on the percentage profit gain $\Delta \Pi \%$; (b) impact of manufacturer's transaction cost on the number of farmers to offer contract $q_{c}^{R}$ under contract farming.

that the cost caused by overstock under suitable weather dominates the cost caused by understock under unsuitable weather. Therefore, the manufacturer should offer less contracts. Positive $D$ means the cost caused by understock under unsuitable weather dominates the cost caused by overstock under suitable weather. In this case, the manufacturer should offer more contracts.

Third, the numerical results indicate that the transaction costs in the spot market also influence the effectiveness of contract farming and the optimal decisions of the manufacturer. Increment in either farmers' or the manufacturer's transaction cost both stimulates the manufacturer into offering contract to more farmers, and the effectiveness of contract farming is also strengthened.

From the results, we can reach some managerial implications. First, compared with purchasing crops from the spot market, contract farming is beneficial for the manufacturer under whichever weather condition. Second, to cope with contract reneging risk caused by weather uncertainty, the manufacturer does not need to set a high contract price to ensure farmers honour the contract under both weather conditions. It is a good choice for the manufacturer to set a relatively lower contract price just to guarantee that the farmers will not renege under suitable weather condition and then offer a counteroffer with a higher price to farmers who renege after the spot price is realized. Third, the manufacturer should contract with more farmers when the unsuitable weather condition is more likely to happen or the transaction cost on the spot market rises. However, she should be careful in deciding contract number as the impact intensity of the unsuitable weather changes. The manufacturer should contract with more farmers as the impact intensity of the unsuitable weather increases if it is lower than a threshold. If the impact intensity of the unsuitable weather exceeds the threshold, the manufacturer should contract with less farmers as there may be less demand for the final product since the price of the product may be very high because of the high cost of purchasing expensive crops due to less yield of the crop.

\section{Conclusions}

Weather risk leads to uncertainty of both the yield and price and further influences the willingness of farmers to participate in contract farming and honour the contract. In this study, we develop a multistage game between a profit-maximizing manufacturer and multiple identical farmers under weather risk and investigate the optimal decisions of the manufacturer, considering the behaviour of farmers.

We discuss two different cases. In the first case, the manufacturer sets a contract price to ensure farmers to honour the contract in any weather condition. While in the second case, the manufacturer sets a lower contract price, only to guarantee that farmers will not renege under certain weather conditions. And she has a second chance to purchase crops from the reneged farmers at a renegotiated price. We derive the optimal decisions of the manufacturer in both cases and numerically investigate the sensitivity of the effectiveness of contract farming and the manufacturer's optimal decisions to model parameters. The results testify the effectiveness of contract farming under whichever weather condition and provide the manufacturer with an optimal strategy to cope with weather risk. Based on these results, some managerial implications are derived.

We believe that our study has generated some useful insights. Nevertheless, it is useful to discuss the limitations of our research. We describe weather conditions by a discrete variable with two values denoting suitable weather or unsuitable weather and suppose two discrete yields under these two weather conditions. An interesting extension would be considered a continuous function of crop yield on weather 
TABLE 9: The optimal production quantity $q_{m}^{N R}$ under different weather conditions in Case 1.

\begin{tabular}{|c|c|c|c|}
\hline$q_{m}^{N R}(w=1), q_{m}^{N R}(w=0)$ & & $w=0$ & \\
\hline$w=1$ & $q_{c} \underline{y} \leq\left(a-p_{s}(\underline{y})-c_{m}-c_{p}\right) / 2 b$ & $\begin{array}{l}\left(a-p_{s}(y)-c_{m}-c_{p}\right) / 2 b \\
<q_{c} \underline{y} \leq\left(a-h-c_{p}\right) / 2 b\end{array}$ & $q_{c} \underline{y}>\left(a-h-c_{p}\right) / 2 b$ \\
\hline$q_{c} \bar{y} \leq\left(a-p_{s}(\bar{y})-c_{m}-c_{p}\right) / 2 b$ & $\begin{array}{l}\left(a-p_{s}(\bar{y})-c_{m}-c_{p}\right) / 2 b \\
\left(a-p_{s}(\underline{y})-c_{m}-c_{p}\right) / 2 b\end{array}$ & - & - \\
\hline $\begin{array}{l}\left(a-p_{s}(\bar{y})-c_{m}-c_{p}\right) / 2 b< \\
q_{c} \bar{y} \leq\left(a-h-c_{p}\right) / 2 b\end{array}$ & $q_{c} \bar{y},\left(a-p_{s}(\underline{y})-c_{m}-c_{p}\right) / 2 b$ & - & $-^{1}$ \\
\hline$q_{c} \bar{y}>\left(a-h-c_{p}\right) / 2 b$ & $\begin{array}{c}\left(a-h-c_{p}\right) / 2 b \\
\left(a-p_{s}(y)-c_{m}-c_{p}\right) / 2 b\end{array}$ & $\left(a-h-c_{p}\right) / 2 b, q_{c} \underline{y}$ & $\begin{array}{l}\left(a-h-c_{p}\right) / 2 b \\
\left(a-h-c_{p}\right) / 2 b\end{array}$ \\
\hline
\end{tabular}

1 “-" denotes that the situation will not happen, and neither $q_{m}^{N R}(w=1)$ nor $q_{m}^{N R}(w=0)$ exists.

$\begin{array}{cccccc}\mathrm{I} & \mathrm{II} & \mathrm{III} & \mathrm{IV} & \mathrm{V} & \mathrm{V} \\ \mathrm{a}-p_{s}(\bar{y})-c_{M}-c_{p} / 2 b \bar{y} & a-h-c_{p} / 2 b \bar{y} & & a-p_{s}(\underline{y})-c_{M}-c_{p} / 2 b \underline{y} & a-h-c_{p} / 2 b \underline{y} & q_{c}\end{array}$

FIgURE 5: Five intervals of $q_{c}$ according to Table 9.

conditions. Additionally, we suppose all the farmers are identical in this study. Another extension is to explore the heterogeneity of farmers and examine its influence on the optimal decisions and the effectiveness of contract farming.

\section{Appendix}

Proof. of Proposition 1. The proof uses the first- and secondorder derivatives with respect to $q_{m}$. To compute the derivatives, we need to rewrite $\Pi\left(q_{m} \mid p_{c}, q_{c}, y(w)\right)$ according to the relationship between $q_{m}$ and $q_{c} y(w)$. We substitute $x=q_{c} y(w)$ into equation (1) and rewrite $\Pi\left(q_{m} \mid p_{c}, q_{c}, y(w)\right)$ as follows.

(1) If $q_{m}>q_{c} y(w)$, then $\Pi\left(q_{m} \mid p_{c}, q_{c}, y(w)\right)=-p_{c} q_{c} y$ $(w)-\left(p_{s}(y(w))+c_{m}\right) \quad\left(q_{m}-q_{c} y(w)\right)-c_{p} q_{m}+$ $\left(a-b q_{m}\right) q_{m}$.

$$
\frac{\partial \Pi\left(q_{m} \mid p_{c}, q_{c}, y(w)\right)}{\partial q_{m}}=-\left(p_{s}(y(w))+c_{m}\right)-c_{p}+a-2 b q_{m}
$$$$
\frac{\partial^{2} \Pi\left(q_{m} \mid p_{c}, q_{c}, y(w)\right)}{\partial q_{m}^{2}}=-2 b<0
$$

Therefore, $\Pi\left(q_{m} \mid p_{c}, q_{c}, y(w)\right)$ is concave in $q_{m}$ when $q_{m}>q_{c} y(w)$. Let $q_{m}^{N R}=\left(a-h-c_{p}\right) / 2 b$, we get $q_{m}=\left(a-p_{s}(y(w))-c_{m}-c_{p}\right) / 2 b$, then the optimal value of $q_{m}$ is

$$
q_{m}=\max \left\{q_{c} y(w), \frac{a-p_{s}(y(w))-c_{m}-c_{p}}{2 b}\right\} \text {. }
$$

(2) If $q_{m}<q_{c} y(w)$, then $\Pi\left(q_{m} \mid p_{c}, q_{c}, y(w)\right)=$ $-p_{c} q_{c} y(w)-h\left(q_{m}-q_{c} y(w)\right)-c_{p} q_{m}+\left(a-b q_{m}\right) q_{m}$. $\frac{\partial \Pi\left(q_{m} \mid p_{c}, q_{c}, y(w)\right)}{\partial q_{m}}=-h-c_{p}+a-2 b q_{m}$,

$\frac{\partial^{2} \Pi\left(q_{m} \mid p_{c}, q_{c}, y(w)\right)}{\partial q_{m}^{2}}=-2 b<0$.

Therefore, $\Pi\left(q_{m} \mid p_{c}, q_{c}, y(w)\right)$ is concave in $q_{m}$ when $\quad q_{m}<q_{c} y(w)$. Let ӘП $\left(q_{m} \mid p_{c}, q_{c}, y(w)\right) / \partial q_{m}=0, \quad$ we get $q_{m}=\left(a-h-c_{p}\right) / 2 b$, then the optimal value of $q_{m}$ is

$$
q_{m}=\min \left\{q_{c} y(w), \frac{a-h-c_{p}}{2 b}\right\} .
$$

(3) If $q_{m}=q_{c} y(w)$, then $\Pi\left(q_{m} \mid p_{c}, q_{c}, y(w)\right)=$ $-p_{c} q_{c} y(w)-c_{p} q_{m}+\left(a-b q_{m}\right) q_{m}$. When $q_{m} \longrightarrow\left(q_{c} y(w)\right)^{-}, \quad \Pi\left(q_{m} \mid p_{c}, q_{c}, y(w)\right)=-p_{c} q_{c} y$ $(w)+h\left(q_{c} y(w)-q_{m}\right)-c_{p} q_{m}+\left(a-b q_{m}\right) q_{m}$, the left derivative of $\Pi\left(q_{m} \mid p_{c}, q_{c}, y(w)\right)$ on $q_{m}$ at $q_{m}=$ $q_{c} y(w)$ is $-h-c_{p}+a-2 b q_{m}$. When $q_{m} \longrightarrow$ $\left(q_{c} y(w)\right)^{+}, \quad \Pi\left(q_{m} \mid p_{c}, q_{c}, \bar{y}\right)=-p_{c} q_{c} \bar{y} \quad-$ $\left(p_{s}(\bar{y})+c_{m}\right)\left(q_{m}-q_{c} \bar{y}\right)-c_{p} q_{m}+\left(a-b q_{m}\right) q_{m}$, the right derivative of $\Pi\left(q_{m} \mid p_{c}, q_{c}, y(w)\right)$ on $q_{m}$ at $q_{m}=$ $q_{c} y(w)$ is $-\left(p_{s}(y(w))+c_{m}\right)-c_{p}+a-2 b q_{m}$. The left and right derivatives are not equal; therefore, $\Pi\left(q_{m} \mid p_{c}, q_{c}, y(w)\right)$ is not derivative on $q_{m}$ at $q_{m}=q_{c} y(w)$.

Conclusively, $q_{m}>q_{c} y(w)$ is continuous and piecewise differentiable on $q_{m}$ and has break point at 
$q_{m}=q_{c} y(w)$. The optimal values of $q_{m}$ can be derived from the above analysis as follows:

$$
q_{m}^{N R}= \begin{cases}\frac{a-p_{s}(y(w))-c_{m}-c_{p}}{2 b}, & \text { when } q_{c} y(w) \leq \frac{a-p_{s}(y(w))-c_{m}-c_{p}}{2 b}, \\ q_{c} y(w), & \text { when } \frac{a-p_{s}(y(w))-c_{m}-c_{p}}{2 b}<q_{c} y(w) \leq \frac{a-h-c_{p}}{2 b}, \\ \frac{a-h-c_{p}}{2 b}, & \text { when } q_{c} y(w)>\frac{a-h-c_{p}}{2 b} .\end{cases}
$$

Proof. of Proposition 2. We first show the proof for the optimal value of contract price $p_{c}^{N R}$. The derivative of $E\left(\Pi\left(p_{c}, q_{c}\right)\right)$ on $p_{c}$ is $\left(\partial E\left(\Pi\left(p_{c}, q_{c}\right)\right) / \partial p_{c}\right)=-q_{c}(\theta \bar{y}+$ $(1-\theta) y)<0$; therefore, $E\left(\Pi\left(p_{c}, q_{c}\right)\right)$ is decreasing in $p_{c}$. Since it is required that $p_{c} \geq p_{s}(\bar{y})-c_{f}$ and $p_{c} \geq p_{s}(y)-c_{f}$ in Case 1 , the optimal value of contract price in Case 1 is $p_{c}^{N R}=p_{s}(y)-c_{f}$.

To derive the optimal value of $q_{c}$, we need to substitute $p_{c}^{N R}$ and $q_{m}^{N R}$ into equation (5) and get a complete expression for $E\left(\Pi\left(p_{c}, q_{c}\right)\right)$ first. According to the expression of $q_{m}^{N R}$ in different situations shown in Corollary 1, we talk about the following cases.

(1) $\left(T A_{1} / \bar{y}\right) \leq\left(T A_{2} / y\right)$

According to this table, we talk about the optimal values of $q_{c}$ on five intervals as shown in Figure 5.

In interval $\mathrm{I}$, when $w=1$,

$$
\begin{aligned}
q_{m}^{N R}= & \frac{a-p_{s}(\bar{y})-c_{m}-c_{p}}{2 b}, \\
P A\left(p_{c}^{N R}, q_{c}, \bar{y}\right)= & \left(p_{s}(\bar{y})+c_{m}-p_{c}^{N R}\right) q_{c} \bar{y} \\
& +\frac{\left(a-p_{s}(\bar{y})-c_{m}-c_{p}\right)^{2}}{4 b} .
\end{aligned}
$$

When $w=0$,

$$
\begin{aligned}
q_{m}^{N R}= & \frac{a-p_{s}(\underline{y})-c_{m}-c_{p}}{2 b}, \\
P A\left(p_{c}^{N R}, q_{c}, \underline{y}\right)= & \left(p_{s}(\underline{y})+c_{m}-p_{c}^{N R}\right) q_{c} \underline{y} \\
& +\frac{\left(a-p_{s}(\underline{y})-c_{m}-c_{p}\right)^{2}}{4 b} .
\end{aligned}
$$

Then, $E\left(\Pi\left(p_{c}^{N R}, q_{c}\right)\right)=\theta P A\left(p_{c}^{N R}, q_{c}, \bar{y}\right)+(1-\theta)$ $P A\left(p_{c}^{N R}, q_{c}, y\right)$. The first-order derivation of $E(\Pi$ $\left.\left(p_{c}^{N R}, q_{c}\right)\right)$ on $q_{c}$ is $\left(\partial E\left(\Pi\left(p_{c}^{N R}, q_{c}\right)\right) / \partial q_{c}\right)=\theta \bar{y}\left(p_{s}\right.$ $\left.(\bar{y})+c_{m}-p_{c}^{N R}\right)+(1-\theta) \quad y\left(p_{s}(y)+c_{m}-p_{c}^{N R}\right)$. Note that, this derivative denotes the expected gain of the manufacturer from contract farming compared with buying crops from the spot market, and it should be positive; otherwise, the manufacturer will not adopt contract farming. Therefore, $E\left(\Pi\left(p_{c}^{N R}, q_{c}\right)\right)$ achieves maximum at $q_{c}=\left(a-p_{s}(\bar{y})-c_{m}-c_{p}\right) / 2 b \bar{y}$.

In interval II, when $w=1$,

$$
\begin{aligned}
q_{m}^{N R} & =q_{c} \bar{y} \\
P A\left(p_{c}^{N R}, q_{c}, \bar{y}\right) & =-p_{c}^{N R} q_{c} \bar{y}-c_{p} q_{c} \bar{y}+\left(a-b q_{c} \bar{y}\right) q_{c} \bar{y} .
\end{aligned}
$$

When $w=0$,

$$
\begin{aligned}
q_{m}^{N R}= & \frac{a-p_{s}(\underline{y})-c_{m}-c_{p}}{2 b}, \\
P A\left(p_{c}^{N R}, q_{c}, \underline{y}\right)= & \left(p_{s}(\underline{y})+c_{m}-p_{c}^{N R}\right) q_{c} \underline{y} \\
& +\frac{\left(a-p_{s}(\underline{y})-c_{m}-c_{p}\right)^{2}}{4 b} .
\end{aligned}
$$

Then, $E\left(\Pi\left(p_{c}^{N R}, q_{c}\right)\right)=\theta P A\left(p_{c}^{N R}, q_{c}, \bar{y}\right)+(1-\theta) P A$ $\left(p_{c}^{N R}, q_{c}, y\right)$. The first- and second-order derivatives of $E\left(\Pi\left(\vec{p}_{c}^{N R}, q_{c}\right)\right)$ on $q_{c}$ are

$$
\begin{aligned}
\frac{\partial E\left(\Pi\left(p_{c}^{N R}, q_{c}\right)\right)}{\partial q_{c}}= & \theta \bar{y}\left(a-p_{c}^{N R}-c_{p}-2 b \bar{y} q_{c}\right) \\
& +(1-\theta) \underline{y}\left(p_{s}(\underline{y})+c_{m}-p_{c}^{N R}\right), \\
\frac{\partial^{2} E\left(\Pi\left(p_{c}^{N R}, q_{c}\right)\right)}{\partial q_{c}^{2}}= & -2 \theta b \bar{y}^{2}<0 .
\end{aligned}
$$

Therefore, $E\left(\Pi\left(p_{c}^{N R}, q_{c}\right)\right)$ is concave on $q_{c}$ in interval II. To derive the optimal value of $q_{c}$ in interval II, we compute the first-order derivation $\partial E\left(\Pi\left(p_{c}^{N R}, q_{c}\right)\right)$ / $\partial q_{c}$ of $E\left(\Pi\left(p_{c}^{N R}, q_{c}\right)\right)$ on $q_{c}$ at the two endpoints of interval II as follows: 


$$
\begin{gathered}
\left.\frac{\partial E\left(\Pi\left(p_{c}^{N R}, q_{c}\right)\right)}{\partial q_{c}}\right|_{q_{c}=\left(a-p_{s}(\bar{y})-c_{m}-c_{p}\right) / 2 b \bar{y}}=\theta \bar{y}\left(p_{s}(\bar{y})+c_{M}-p_{c}^{N R}\right)+(1-\theta) \underline{y}\left(p_{s}(\underline{y})+c_{m}-p_{c}^{N R}\right)>0 \\
\left.\frac{\partial E\left(\Pi\left(p_{c}^{N R}, q_{c}\right)\right)}{\partial q_{c}}\right|_{q_{c}=\left(a-h-c_{p}\right) / 2 b \bar{y}}=\theta \bar{y}\left(h-p_{s}(\underline{y})+c_{f}\right)+(1-\theta) \underline{y}\left(c_{m}+c_{f}\right) .
\end{gathered}
$$

If $\theta \bar{y}\left(h-p_{s}(y)+c_{f}\right)+(1-\theta) y\left(c_{m}+c_{f}\right)>0$, then $E\left(\Pi\left(p_{c}^{N R}, q_{c}\right)\right)$ increases with $q_{c}$ in interval II, and the optimal value of $q_{c}$ in interval II is $\left(a-h-c_{p}\right) / 2 b \bar{y}$; otherwise, $E\left(\Pi\left(p_{c}^{N R}, q_{c}\right)\right)$ first increases and then decreases in interval II. Let $\left(\partial E\left(\Pi\left(p_{c}^{N R}, q_{c}\right)\right) / \partial q_{c}\right)=0$, we get the optimal value of $q_{c}$ in interval II as $\left(\theta \bar{y}\left(a-p_{s}(y)+c_{f}-c_{p}\right)+\right.$ $\left.(1-\theta) \underline{y}\left(c_{m}+c_{f}\right)\right) / 2 b \theta \bar{y}^{2}$.

In interval III, when $w=1$,

$$
q_{m}^{N R}=\frac{a-h-c_{p}}{2 b}
$$

$P A\left(p_{c}^{N R}, q_{c}, \bar{y}\right)=\left(h-p_{c}^{N R}\right) q_{c} \bar{y}+\frac{\left(a-h-c_{p}\right)^{2}}{4 b}$.

When $w=0$,

$$
\begin{aligned}
q_{m}^{N R}= & \frac{a-p_{s}(\underline{y})-c_{m}-c_{p}}{2 b}, \\
P A\left(p_{c}^{N R}, q_{c}, \underline{y}\right)= & \left(p_{s}(\underline{y})+c_{m}-p_{c}^{N R}\right) q_{c} \underline{y} \\
& +\frac{\left(a-p_{s}(\underline{y})-c_{m}-c_{p}\right)^{2}}{4 b} .
\end{aligned}
$$

$$
\begin{aligned}
& \frac{\partial E\left(\Pi\left(p_{c}^{N R}, q_{c}\right)\right)}{\partial q_{c}}=\theta \bar{y}\left(h-p_{c}^{N R}\right)+(1-\theta) \underline{y}\left(a-p_{c}^{N R}-c_{p}\right)-2(1-\theta) b \underline{y} \underline{{ }^{2}}, \\
& \frac{\partial^{2} E\left(\Pi\left(p_{c}^{N R}, q_{c}\right)\right)}{\partial q_{c}^{2}}=-2(1-\theta) \underline{b} \underline{y}<0 .
\end{aligned}
$$

Therefore, $E\left(\Pi\left(p_{c}^{N R}, q_{c}\right)\right)$ is concave on $q_{c}$ in interval IV. To derive the optimal value of $q_{c}$ in interval IV, we compute the first-order derivation
Then, $E\left(\Pi\left(p_{c}^{N R}, q_{c}\right)\right)=\theta P A \quad\left(p_{c}^{N R}, q_{c}, \bar{y}\right)+(1-\theta)$ $P A\left(p_{c}^{N R}, q_{c}, y\right)$. The first-order derivation of $E\left(\Pi\left(p_{c}^{N R}, q_{c}\right)\right)$ on $q_{c}$ is

$$
\frac{\partial E\left(\Pi\left(p_{c}^{N R}, q_{c}\right)\right)}{\partial q_{c}}=\theta \bar{y}\left(h-p_{s}(\underline{y})+c_{f}\right)+(1-\theta) \underline{y}\left(c_{m}+c_{f}\right) \text {. }
$$

If $\theta \bar{y}\left(h-p_{s}(y)+c_{f}\right)+(1-\theta) \underline{y}\left(c_{m}+c_{f}\right)>0$, then $E\left(\Pi\left(p_{c}^{N R}, q_{c}\right)\right)$ increases with $q_{c}$ in interval III, and the optimal value of $q_{c}$ in interval III is $\left(a-p_{s}(y)-c_{m}-c_{p}\right) / 2 b y$; otherwise, $E\left(\Pi\left(p_{c}^{N R}, q_{c}\right)\right)$ decreases with $q_{c}$ in interval III, and the optimal value of $q_{c}$ in interval III is $\left(a-h-c_{p}\right) / 2 b \bar{y}$.

In interval IV, when $w=1, q_{m}^{N R}=\left(a-h-c_{p}\right) / 2 b$, PA $\left(p_{c}^{N R}, q_{c}, \bar{y}\right)=\left(h-p_{c}^{N R}\right) q_{c} \bar{y}+\left(\left(a-h-c_{p}\right)^{2} / 4 b\right)$.

When $w=0$,

$$
q_{m}^{N R}=q_{c} \underline{y}
$$$$
P A\left(p_{c}^{N R}, q_{c}, \underline{y}\right)=\left(a-p_{c}^{N R}-c_{p}\right) q_{c} \underline{y}-b \underline{y} q_{c}^{2} .
$$

Then, $E\left(\Pi\left(p_{c}^{N R}, q_{c}\right)\right)=\theta P A p_{c}^{N R}\left(p_{c}, q_{c}, \bar{y}\right)+(1-\theta)$ $P A\left(p_{c}^{N R}, q_{c}, y\right)$. The first- and second-order derivatives of $E\left(\bar{\Pi}\left(p_{c}^{N R}, q_{c}\right)\right)$ on $q_{c}$ are $\partial E\left(\Pi\left(p_{c}^{N R}, q_{c}\right)\right) / \partial q_{c}$ of $E\left(\Pi\left(p_{c}^{N R}, q_{c}\right)\right)$ on $q_{c}$ at the two endpoints of interval IV as follows:

$$
\begin{aligned}
& \left.\frac{\partial E\left(\Pi\left(p_{c}^{N R}, q_{c}\right)\right)}{\partial q_{c}}\right|_{q_{c}=\left(a-p_{s}(\underline{y})-c_{m}-c_{p}\right) / 2 b \underline{y}}=\theta \bar{y}\left(h-p_{s}(\underline{y})+c_{f}\right)+(1-\theta) \underline{y}\left(c_{m}+c_{f}\right), \\
& \left.\frac{\partial E\left(\Pi\left(p_{c}^{N R}, q_{c}\right)\right)}{\partial q_{c}}\right|_{q_{c}=\left(a-p_{s}(\underline{y})-c_{m}-c_{p}\right) / 2 b \underline{y}}=\theta \bar{y}\left(h-p_{s}(\underline{y})+c_{f}\right)+(1-\theta) \underline{y}\left(c_{m}+c_{f}\right) .
\end{aligned}
$$

If $\theta \bar{y}\left(h-p_{s}(y)+c_{f}\right)+(1-\theta) y\left(c_{m}+c_{f}\right)>0$, then $E\left(\Pi\left(p_{c}^{N R}, q_{c}\right)\right)$ first increases and then decreases in interval IV. Let $\left(\partial E\left(\Pi\left(p_{c}^{N R}, q_{c}\right)\right) / \partial q_{c}\right)=0$, we get the optimal value of $q_{c}$ in interval IV as follows: $(\theta \bar{y}(h-$ 
$\left.\left.p_{s}(\underline{y})+c_{f}\right) \quad+(1-\theta) \underline{y}\left(a-p_{s}(\underline{y})+c_{f}-c_{p}\right)\right) /$ $2 b(\overline{1}-\theta) \underline{y}^{2}$; otherwise, $\left.E \overline{(\Pi}\left(p_{c}^{N R}, \overline{q_{c}}\right)\right)$ decreases with $q_{c}$ in interval IV, and the optimal value of $q_{c}$ in interval IV is $\left(a-p_{s}(\underline{y})-c_{m}-c_{p}\right) / 2 b \underline{y}$.

In interval $\mathrm{V}$, when $w=1$,

$$
q_{m}^{N R}=\frac{a-h-c_{p}}{2 b}
$$

$P A\left(p_{c}^{N R}, q_{c}, \bar{y}\right)=\left(h-p_{c}^{N R}\right) q_{c} \bar{y}+\frac{\left(a-h-c_{p}\right)^{2}}{4 b}$.

When $w=0$,

$$
q_{m}^{N R}=\frac{a-h-c_{p}}{2 b}
$$

$$
P A\left(p_{c}^{N R}, q_{c}, \underline{y}\right)=\left(h-p_{c}^{N R}\right) q_{c} \underline{y}+\frac{\left(a-h-c_{p}\right)^{2}}{4 b} .
$$

Then, $E\left(\Pi\left(p_{c}^{N R}, q_{c}\right)\right)=\theta P A\left(p_{c}^{N R}, q_{c}, \bar{y}\right)+(1-\theta)$ $P A\left(p_{c}^{N R}, q_{c}, y\right)$. The first-order derivation of $E\left(\Pi\left(p_{c}^{N R}, q_{c}\right)\right)$ on $q_{c}$ is

$\frac{\partial E\left(\Pi\left(p_{c}^{N R}, q_{c}\right)\right)}{\partial q_{c}}=(\theta \bar{y}+(1-\theta) \underline{y})\left(h-p_{s}(\underline{y})+c_{f}\right)<0$.

Therefore, $E\left(\Pi\left(p_{c}^{N R}, q_{c}\right)\right)$ decreases with $q_{c}$ in interval $\mathrm{V}$, and it achieves maximum at $q_{c}=\left(a-h-c_{p}\right) / 2 b y$.

Above all, we can find that the optimal value of $q_{c}$ depends on the value of $\theta \bar{y}\left(h-p_{s}(y)+c_{f}\right)+$ $(1-\theta) y\left(c_{m}+c_{f}\right)$. If $\theta \bar{y}\left(h-p_{s}(y)+c_{f}\right)+(1-\theta)$ $y\left(c_{m}+\bar{c}_{f}\right) \leq 0$, then the optimal value of $q_{c}$ is

$$
\left(\theta \bar{y}\left(a-p_{s}(\underline{y})+c_{f}-c_{p}\right)+(1-\theta) \underline{y}\left(c_{m}+c_{f}\right)\right) / 2 b \theta \bar{y}^{2} \text {. }
$$

if $\theta \bar{y}\left(h-p_{s}(\bar{y})+c_{f}\right)+(1-\theta) y\left(c_{m}+c_{f}\right)>0$, then the optimal value of $q_{c}$ is

$$
\frac{\theta \bar{y}\left(h-p_{s}(\underline{y})+c_{f}\right)+(1-\theta) \underline{y}\left(a-p_{s}(\underline{y})+c_{f}-c_{p}\right)}{2 b(1-\theta) \underline{y}} .
$$

\section{(2) $\left(T A_{1} / \bar{y}\right)>\left(T A_{2} / y\right)$}

In the case that $\left(T A_{1} / \bar{y}\right)>\left(T A_{2} / y\right)$, the analysis is similar with that in the case that $\left(\overline{T A_{1}} / \bar{y}\right) \leq\left(T A_{2} / y\right)$. We omit the proof in this case for brevity.

Proof. of Proposition 3. Similar with Proposition 1, the proof uses the first- and second-order derivatives with respect to $q_{m}$. In Case 2, farmers honour the contract under suitable weather $\left(x=q_{c} \bar{y}\right)$ but renege under unsuitable weather $(x=0)$. Therefore, the profit of the manufacturer $\Pi\left(q_{m} \mid p_{c}, q_{c}, y(w)\right)$ in stage 3 depends on farmers' decisions in stage 2 and is different under the two weather conditions. We will discuss separately.

(1) Under suitable weather conditions, that is, $w=1$, the profit of the manufacturer in stage 3 is $\Pi\left(q_{m} \mid p_{c}, q_{c}\right.$, $\bar{y})=-p_{c} q_{c} \bar{y}-\left(p_{s}(\bar{y})+c_{m}\right)\left(q_{m}-q_{c} \bar{y}\right)^{+}+h$ $\left(q_{c} \bar{y}-q_{m}\right)^{+}-c_{p} q_{m}+\left(a-b q_{m}\right) q_{m}$. In the following, we discuss further according to the relationship between $q_{m}$ and $q_{c} \bar{y}$.

If $q_{m}>q_{c} \bar{y}$, then

$$
\begin{aligned}
\Pi\left(q_{m} \mid p_{c}, q_{c}, \bar{y}\right)= & -p_{c} q_{c} \bar{y}-\left(p_{s}(\bar{y})+c_{m}\right)\left(q_{m}-q_{c} \bar{y}\right) \\
& -c_{p} q_{m}+\left(a-b q_{m}\right) q_{m}
\end{aligned}
$$$$
\frac{\partial \Pi\left(q_{m} \mid p_{c}, q_{c}, \bar{y}\right)}{\partial q_{m}}=-\left(p_{s}(\bar{y})+c_{m}\right)-c_{p}+a-2 b q_{m},
$$

$\frac{\partial^{2} \Pi\left(q_{m} \mid p_{c}, q_{c}, \bar{y}\right)}{\partial q_{m}^{2}}=-2 b<0$.

Therefore, $\Pi\left(q_{m} \mid p_{c}, q_{c}, \bar{y}\right)$ is concave in $q_{m}$ when $q_{m}>q_{c} y(w)$. Let $\left(\partial \Pi\left(q_{m} \mid p_{c}, q_{c}, \bar{y}\right) / \partial q_{m}\right)=0$, we get $q_{m}=\left(a-p_{s}(\bar{y})-c_{m}-c_{p}\right) / 2 b$, and then, the optimal value of $q_{m}$ is $q_{m}=\max \left\{q_{c} \bar{y},\left(a-p_{s}(\bar{y})-\right.\right.$ $\left.\left.c_{m}-c_{p}\right) / 2 b\right\}$.

If $q_{m}<q_{c} \bar{y}$, then

$$
\begin{aligned}
\Pi\left(q_{m} \mid p_{c}, q_{c}, \bar{y}\right) & =-p_{c} q_{c} \bar{y}-h\left(q_{c} \bar{y}-q_{m}\right)-c_{p} q_{m}+\left(a-b q_{m}\right) q_{m}, \\
\frac{\partial \Pi\left(q_{m} \mid p_{c}, q_{c}, \bar{y}\right)}{\partial q_{m}} & =-h-c_{p}+a-2 b q_{m}, \\
\frac{\partial^{2} \Pi\left(q_{m} \mid p_{c}, q_{c}, \bar{y}\right)}{\partial q_{m}^{2}} & =-2 b<0 .
\end{aligned}
$$

Therefore, $\Pi\left(q_{m} \mid p_{c}, q_{c}, \bar{y}\right)$ is concave in $q_{m}$ when $q_{m}<q_{c} \bar{y}$. Let $\left(\partial \Pi\left(q_{m} \mid p_{c}, q_{c}, \bar{y}\right) / \partial q_{m}\right)=0$, we get $q_{m}=\left(a-h-c_{p}\right) / 2 b$, and then, the optimal value of $q_{m}$ is $q_{m}=\min \left\{q_{c} \bar{y},\left(a-h-c_{p}\right) / 2 b\right\}$.

If $q_{m}=q_{c} \bar{y}$, then $\Pi\left(q_{m} \mid p_{c}, q_{c}, \bar{y}\right)=-p_{c} q_{c} \bar{y}-c_{p} q_{m}+$ $\left(a-b q_{m}\right) q_{m}$. When $q_{m} \longrightarrow\left(q_{c} \bar{y}\right)^{-}, \Pi\left(q_{m} \mid p_{c}\right.$, $\left.q_{c}, \bar{y}\right)=-p_{c} q_{c} \bar{y}+h\left(q_{c} \bar{y}-q_{m}\right)-c_{p} q_{m}+\left(a-b q_{m}\right) q_{m}$, the left derivative of $\Pi\left(q_{m} \mid p_{c}, q_{c}, \bar{y}\right)$ on $q_{m}$ at $q_{m}=$ $q_{c} \bar{y}$ is $-h-c_{p}+a-2 b q_{m}$. When $q_{m} \longrightarrow\left(q_{c} \bar{y}\right)^{+}$, $\Pi\left(q_{m} \mid p_{c}, q_{c}, \bar{y}\right)=-p_{c} q_{c} \bar{y}-\left(p_{s}(\bar{y})+c_{m}\right)\left(q_{m}-q_{c} \bar{y}\right)$ - $c_{p} q_{m}+\left(a-b q_{m}\right) q_{m}$, the right derivative of $\Pi\left(q_{m} \mid p_{c}, q_{c}, \bar{y}\right)$ on $q_{m}$ at $q_{m}=q_{c} \bar{y}$ is $-\left(p_{s}(\bar{y})+c_{m}\right)-c_{p}+a-2 b q_{m}$. The left and right derivatives are not equal; therefore, $\Pi\left(q_{m} \mid p_{c}, q_{c}, \bar{y}\right)$ is not derivative on $q_{m}$ at $q_{m}=q_{c} \bar{y}$.

Conclusively, $\Pi\left(q_{m} \mid p_{c}, q_{c}, \bar{y}\right)$ is continuous and piecewise differentiable on $q_{m}$ and has break point at 
$q_{m}=q_{c} \bar{y}$. The optimal values of $q_{m}$ under suitable weather $(w=1)$ can be derived from the above analysis as follows:

$$
q_{m}^{N R}= \begin{cases}\frac{a-p_{s}(\bar{y})-c_{m}-c_{p}}{2 b}, & \text { when } q_{c} \bar{y} \leq \frac{a-p_{s}(\bar{y})-c_{m}-c_{p}}{2 b}, \\ q_{c} \bar{y}, & \text { when } \frac{a-p_{s}(\bar{y})-c_{m}-c_{p}}{2 b}<q_{c} \bar{y} \leq \frac{a-h-c_{p}}{2 b}, \\ \frac{a-h-c_{p}}{2 b}, & \text { when } q_{c} \bar{y}>\frac{a-h-c_{p}}{2 b} .\end{cases}
$$

(2) Under unsuitable weather condition, that is, $w=0$, the profit of the manufacturer in stage 3 is $\Pi\left(q_{m} \mid p_{c}, q_{c}, \underline{y}\right)=-\left(p_{s} \quad(\underline{y})-c_{f}\right) \min \left\{q_{m}, q_{c} \underline{y}\right\}-$ $\left(p_{s}(\underline{y})+c_{m}\right)\left(q_{m}-q_{c} \underline{y}\right)^{+}-c_{p} q_{m}+\left(a-b q_{m}\right) q_{m}$. In the following, we discuss further according to the relationship between $q_{m}$ and $q_{c} \underline{y}$.

If $q_{m}>q_{c} \underline{y}$, then

$$
\begin{aligned}
\Pi\left(q_{m} \mid p_{c}, q_{c}, \underline{y}\right)= & -\left(p_{s}(\underline{y})-c_{f}\right) q_{c} \underline{y} \\
& -\left(p_{s}(\underline{y})+c_{m}\right)\left(q_{m}-q_{c} \underline{y}\right) \\
& -c_{p} q_{m}+\left(a-b q_{m}\right) q_{m}, \\
\frac{\partial \Pi\left(q_{m} \mid p_{c}, q_{c}, \underline{y}\right)}{\partial q_{m}}= & -\left(p_{s}(\underline{y})+c_{m}\right)-c_{p}+a-2 b q_{m}, \\
\frac{\partial^{2} \Pi\left(q_{m} \mid p_{c}, q_{c}, \underline{y}\right)}{\partial q_{m}^{2}}= & -2 b<0 .
\end{aligned}
$$

Therefore, $\Pi\left(q_{m} \mid p_{c}, q_{c}, y\right)$ is concave in $q_{m}$ when $q_{m}>q_{c} y$. Let $\left(\partial \Pi\left(q_{m} \mid \bar{p}_{c}, q_{c}, y\right) / \partial q_{m}\right)=0$, we get $q_{m}=\left(a-p_{s}(\underline{y})-c_{m}-c_{p}\right) / 2 b$, and then, the optimal value of $q_{m}$ is $q_{m}=\max \left\{q_{c} \underline{y},\left(a-p_{s}(\underline{y})-\right.\right.$ $\left.\left.c_{m}-c_{p}\right) / 2 b\right\}$.

If $q_{m}<q_{c} y$, then

$$
\begin{aligned}
& \Pi\left(q_{m} \mid p_{c}, q_{c}, \underline{y}\right)=-\left(p_{s}(\underline{y})-c_{f}\right) q_{m}-c_{p} q_{m}+\left(a-b q_{m}\right) q_{m}, \\
& \frac{\partial \Pi\left(q_{m} \mid p_{c}, q_{c}, \underline{y}\right)}{\partial q_{m}}=-\left(p_{s}(\underline{y})-c_{f}\right)-c_{p}+a-2 b q_{m}, \\
& \frac{\partial^{2} \Pi\left(q_{m} \mid p_{c}, q_{c}, \underline{y}\right)}{\partial q_{m}^{2}}=-2 b<0 .
\end{aligned}
$$

Therefore, $\Pi\left(q_{m} \mid p_{c}, q_{c}, y\right)$ is concave in $q_{m}$ when $q_{m}<q_{c} y$. Let $\left(\partial \Pi\left(q_{m} \mid \bar{p}_{c}, q_{c}, y\right) / \partial q_{m}\right)=0$, we get $q_{m}=\left(\bar{a}-p_{s}(y)+c_{f}-c_{p}\right) / 2 b$, and then, the optimal value of $\overline{q_{m}}$ is $q_{m}=\min \left\{q_{c} \underline{y},\left(a-p_{s}(\underline{y})+\right.\right.$ $\left.\left.c_{f}-c_{p}\right) / 2 b\right\}$.

If $q_{m}=q_{c} \underline{y}$, then $\Pi\left(q_{m} \mid p_{c}, q_{c}, \underline{y}\right)=-\left(p_{s}(\underline{y})-c_{f}\right)$ $q_{m}-c_{p} q_{m}+\left(a-b q_{m}\right) q_{m}$. When $q_{m} \longrightarrow\left(q_{c} \underline{y}\right)^{-}$, $\Pi\left(q_{m} \mid p_{c}, q_{c}, \underline{y}\right)=-\left(p_{s}(\underline{y})-c_{f}\right) q_{m}-c_{p} q_{m}+(a-b$ $\left.q_{m}\right) q_{m}$; therefore, the left derivative of $\Pi\left(q_{m} \mid p_{c}\right.$, $\left.q_{c}, \underline{y}\right)$ on $q_{m}$ at $q_{m}=q_{c} \underline{y}$ is $-\left(p_{s}(\underline{y})-c_{f}\right)-c_{p}$ $+a-2 b q_{m}$. When $q_{m} \longrightarrow\left(q_{c} \underline{y}\right)^{+}, \Pi\left(q_{m} \mid p_{c}\right.$, $\left.q_{c}, \underline{y}\right)=-\left(p_{s} \quad(\underline{y})-c_{F}\right) q_{c} \underline{y}-\left(\bar{p}_{s}(\underline{y})+c_{M}\right)\left(q_{m}{ }^{-}\right.$ $\left.q_{c} \underline{y}\right)-c_{p} q_{m}+\left(a-\bar{b} q_{m}\right) q_{m}$; therefore, the right derivative of $\Pi\left(q_{m} \mid p_{c}, q_{c}, \underline{y}\right)$ on $q_{m}$ at $q_{m}=q_{c} \underline{y}$ is $-\left(p_{s}(y)+c_{m}\right)-c_{p}+a-\overline{2} b q_{m}$. The left and right derivatives are not equal; therefore, $\Pi\left(q_{m} \mid p_{c}, q_{c}, \underline{y}\right)$ is not derivative on $q_{m}$ at $q_{m}=q_{c} \underline{y}$.

Conclusively, $\Pi\left(q_{m} \mid p_{c}, q_{c}, \underline{y}\right)$ is continuous and piecewise differentiable on $q_{m}$ and has break point at $q_{m}=q_{c} y$. The optimal values of $q_{m}$ under suitable weather $(w=0)$ can be derived from the above analysis as follows: 


$$
q_{m}^{N R}= \begin{cases}\frac{a-p_{s}(\underline{y})-c_{m}-c_{p}}{2 b}, & \text { when } q_{c} \underline{y} \leq \frac{a-p_{s}(\underline{y})-c_{m}-c_{p}}{2 b} \\ q_{c} \underline{y}, & \text { when } \frac{a-p_{s}(\underline{y})-c_{m}-c_{p}}{2 b}<q_{c} \underline{y} \leq \frac{a-p_{s}(\underline{y})+c_{f}-c_{p}}{2 b}, \\ \frac{a-p_{s}(\underline{y})+c_{f}-c_{p}}{2 b}, & \text { when } q_{c} \underline{y}>\frac{a-p_{s}(\underline{y})+c_{f}-c_{p}}{2 b} .\end{cases}
$$

Proof. of Proposition 4. We first show the proof for the optimal value of contract price $p_{c}^{R}$. The derivative of $E\left(\Pi\left(p_{c}, q_{c}\right)\right)$ on $p_{c}$ is $\left(\partial E\left(\Pi\left(p_{c}, q_{c}\right)\right) / \partial p_{c}\right)=-q_{c} \theta \bar{y}<0$; therefore, $E\left(\Pi\left(p_{c}, q_{c}\right)\right)$ is decreasing in $p_{c}$. Since it is prescribed that $p_{c} \geq p_{s}(\bar{y})-c_{f}$ and $p_{c}<p_{s}(y)-c_{f}$ in Case 2, the optimal value of the contract price offered to farmers is $p_{c}^{R}=p_{s}(\bar{y})-c_{f}$.

The proof for deriving the optimal value of the number of farmers to offer the contract $q_{c}^{R}$ is similar to that of Proposition 2, and we omit them here for brevity.
Proof. of Proposition 5. (a) Since $p_{c}^{N R}-p_{c}^{N}=\left(\theta \bar{y}\left(p_{s}(y)-\right.\right.$ $\left.\left.p_{s}(\bar{y})\right) /(\theta \bar{y}+(1-\theta) y)\right)>0$ and $p_{c}^{N}-p_{c}^{R}=\left((1-\theta) \underline{y}\left(p_{s}(y)-p_{s}(\bar{y})\right) /(\theta \bar{y}+(1-\theta) y)\right)>0$ hold, $p_{c}^{N R}-p_{c}^{R}>0$ holds. In the following, we prove (b) and (c) together. It is easy to prove that $A-D=B-E=C-F=p_{s}(\bar{y})-p_{s}(y)<0$. According to Table 1 (Table 2) and Table 3 (Table 4 ), we can compare $q_{c}^{N R}$ $\left(E\left(\Pi\left(p_{c}^{N R}, q_{c}^{N R}\right)\right)\right)$ and $q_{c}^{R}\left(E\left(\Pi\left(p_{c}^{R}, q_{c}^{R}\right)\right)\right)$ as follows:

(1) when $\left(T A_{1} / \bar{y}\right) \leq\left(T A_{2} / y\right)$ If $0<A<D$, then

$$
\begin{gathered}
q_{c}^{N R}-q_{c}^{R}=\frac{\theta \bar{y}\left(p_{s}(\bar{y})-p_{s}(\underline{y})\right)}{2 b(1-\theta) \underline{\underline{y}}}<0, \\
E\left(\Pi\left(p_{c}^{N R}, q_{c}^{N R}\right)\right)-E\left(\Pi\left(p_{c}^{R}, q_{c}^{R}\right)\right)=b(1-\theta)^{2} \underline{y}\left(\left(q_{c}^{N R}\right)^{2}-\left(q_{c}^{R}\right)^{2}\right)<0 .
\end{gathered}
$$

If $A \leq 0<D$, then

$$
\begin{aligned}
q_{c}^{N R}-q_{c}^{R} & =\frac{\theta \bar{y}(1-\theta) \underline{y}(\underline{y}-\bar{y})\left(a-p_{s}(\underline{y})+c_{f}-c_{p}\right)+(1-\theta)^{2} \underline{y}\left(c_{m}+c_{f}\right)-\theta^{2} \bar{y}^{3}\left(h-p_{s}(\bar{y})+c_{f}\right)}{2 b \theta(1-\theta) \bar{y}^{2} \underline{y}} \\
& <\frac{\theta \bar{y}(1-\theta) \underline{y}(\underline{y}-\bar{y})\left(a-p_{s}(\underline{y})+c_{f}-c_{p}\right)+(1-\theta)^{2} \underline{y}\left(c_{m}+c_{f}\right)+\theta \bar{y}^{2}(1-\theta) \underline{y}\left(c_{m}+c_{f}\right)}{2 b \theta(1-\theta) \bar{y}^{2} \underline{y}} \\
= & \frac{(1-\theta) \underline{y}\left(c_{m}+c_{f}\right)+\theta \bar{y} \underline{y}\left(a-p_{s}(\underline{y})+c_{f}-c_{p}\right)-\theta \bar{y}^{2}\left(a-p_{s}(\underline{y})-c_{m}-c_{p}\right)}{2 b \theta \bar{y}^{2} \underline{y}} \\
\leq & \frac{-\theta \bar{y} \underline{y}\left(h-p_{s}(\underline{y})+c_{f}\right)+\theta \bar{y} \underline{y}\left(a-p_{s}(\underline{y})+c_{f}-c_{p}\right)-\theta \bar{y}^{2}\left(a-p_{s}(\underline{y})-c_{m}-c_{p}\right)}{2 b \theta \bar{y}^{2} \underline{y}} \\
= & \frac{1}{2 b}\left(\frac{a-h-c_{p}}{\bar{y}}-\frac{a-p_{s}(\underline{y})-c_{m}-c_{p}}{y}\right)=\frac{1}{2 b}\left(\frac{T A_{1}}{\bar{y}}-\frac{T A_{2}}{y}\right) \leq 0, \\
E\left(\Pi\left(p_{c}^{N R}, q_{c}^{N R}\right)\right)-E\left(\Pi\left(p_{c}^{R}, q_{c}^{R}\right)\right)= & \frac{1}{4 b}\left(\theta\left(\left(2 b \bar{y} q_{c}^{N R}\right)^{2}-\left(a-h-c_{p}\right)^{2}\right)-(1-\theta)\left(\left(2 b \underline{y} q_{c}^{R}\right)^{2}-\left(a-p_{s}(\underline{y})-c_{m}-c_{p}\right)^{2}\right)\right) \\
= & \frac{\theta}{4 b}\left(2 b \bar{y} q_{c}^{N R}+\left(a-h-c_{p}\right)\right)\left(2 b \bar{y} q_{c}^{N R}-\left(a-h-c_{p}\right)\right) \\
& -\frac{1-\theta}{4 b}\left(2 b \underline{y} q_{c}^{R}+\left(a-p_{s}(\underline{y})-c_{m}-c_{p}\right)\right)\left(2 b \underline{y} q_{c}^{R}-\left(a-p_{s}(\underline{y})-c_{m}-c_{p}\right)\right),
\end{aligned}
$$


where

$$
\begin{aligned}
& 2 b \bar{y} q_{c}^{N R}+\left(a-h-c_{p}\right)=\left(a-p_{s}(\underline{y})+c_{f}-c_{p}\right)+\frac{(1-\theta) \underline{y}}{\theta \bar{y}}\left(c_{m}+c_{f}\right)+\left(a-h-c_{p}\right)>0, \\
& 2 b \bar{y} q_{c}^{N R}-\left(a-h-c_{p}\right)=\left(h-p_{s}(\underline{y})+c_{f}\right)+\frac{(1-\theta) \underline{y}}{\theta \bar{y}}\left(c_{m}+c_{f}\right) \leq 0, \\
& 2 b \underline{y} q_{c}^{R}-\left(a-p_{s}(\underline{y})-c_{m}-c_{p}\right)=\frac{\theta \bar{y}}{(1-\theta) \underline{y}}\left(h-p_{s}(\bar{y})+c_{f}\right)+\left(c_{m}+c_{f}\right)>0, \\
& 2 b \underline{y} q_{c}^{R}+\left(a-p_{s}(\underline{y})-c_{m}-c_{p}\right)>2 b \underline{y} q_{c}^{R}-\left(a-p_{s}(\underline{y})-c_{m}-c_{p}\right)>0 .
\end{aligned}
$$

Therefore, $E\left(\Pi\left(p_{c}^{N R}, q_{c}^{N R}\right)\right)-E\left(\Pi\left(p_{c}^{R}, q_{c}^{R}\right)\right)<0$.

If $A<D \leq 0$, then

$$
\begin{gathered}
q_{c}^{N R}-q_{c}^{R}=\frac{p_{s}(\bar{y})-p_{s}(\underline{y})}{2 b \bar{y}}<0, \\
E\left(\Pi\left(p_{c}^{N R}, q_{c}^{N R}\right)\right)-E\left(\Pi\left(p_{c}^{R}, q_{c}^{R}\right)\right)=b \theta \bar{y}^{2}\left(\left(q_{c}^{N R}\right)^{2}-\left(q_{c}^{R}\right)^{2}\right)<0 .
\end{gathered}
$$

(2) when $\left(T A_{2} / \underline{y}\right)<\left(T A_{1} / \bar{y}\right) \leq\left(T A_{3} / \underline{y}\right)$ and $C \leq E$

If $0<B<C \leq E<F$, then

$$
\begin{gathered}
q_{c}^{N R}-q_{c}^{R}=\frac{\theta \bar{y}\left(p_{s}(\bar{y})-p_{s}(\underline{y})\right)}{2 b(1-\theta) \underline{\underline{y}}}<0, \\
E\left(\Pi\left(p_{c}^{N R}, q_{c}^{N R}\right)\right)-E\left(\Pi\left(p_{c}^{R}, q_{c}^{R}\right)\right)=b(1-\theta)^{2} \underline{y}\left(\left(q_{c}^{N R}\right)^{2}-\left(q_{c}^{R}\right)^{2}\right)<0 .
\end{gathered}
$$

If $B \leq 0<C<E<F$, then 


$$
\begin{aligned}
q_{c}^{N R}-q_{c}^{R}= & \frac{\theta \bar{y}(1-\theta) \underline{y}(\underline{y}-\bar{y})\left(a-p_{s}(\underline{y})+c_{f}-c_{p}\right)-\theta \bar{y}\left(\theta \bar{y}^{2}+(1-\theta) \underline{y}\right)\left(h-p_{s}(\bar{y})+c_{f}\right)}{2 b(1-\theta) \underline{y}\left(\theta \bar{y}^{2}+(1-\theta) \underline{y}\right)} \\
< & \frac{\theta \bar{y}(1-\theta) \underline{y}(\underline{y}-\bar{y})\left(a-p_{s}(\underline{y})+c_{f}-c_{p}\right)+\left(\theta \bar{y}^{2}+(1-\theta) \underline{y}\right)(1-\theta) \underline{y}\left(a-p_{s}(\underline{y})+c_{f}-c_{p}-(\underline{y} / \bar{y})\left(a-h-c_{p}\right)\right)}{2 b(1-\theta)^{2}\left(\theta \bar{y}^{2}+(1-\theta) \underline{y}\right)} \\
= & \frac{\theta \underline{y} \underline{y}\left(h-p_{s}(\underline{y})+c_{f}\right)+(1-\theta) \underline{y}\left(\left(a-p_{s}(\underline{y})+c_{f}-c_{p}\right) / \underline{y}-\left(a-h-c_{p}\right) / \bar{y}\right)}{2 b \underline{y}\left(\theta \bar{y}^{2}+(1-\theta) \underline{y}\right)} \\
\leq & \frac{-(1-\theta) \underline{y}\left(a-p_{s}(\underline{y})+c_{f}-c_{p}-(\underline{y} / \bar{y})\left(a-h-c_{p}\right)\right)+(1-\theta)^{2}\left(a-p_{s}(\underline{y})+c_{f}-c_{p}\right)-(1-\theta)(\underline{y} / \bar{y})\left(a-h-c_{p}\right)}{2 b \underline{y}\left(\theta \bar{y}^{2}+(1-\theta) \underline{y}\right)} \\
= & 0, \\
& E\left(\Pi\left(p_{c}^{N R}, q_{c}^{N R}\right)\right)-E\left(\Pi\left(p_{c}^{R}, q_{c}^{R}\right)\right)=\frac{1}{4 b}\left(\theta\left(\left(2 b \bar{y} q_{c}^{N R}\right)^{2}-\left(a-h-c_{p}\right)^{2}\right)+(1-\theta)\left(\left(2 b \underline{y} q_{c}^{N R}\right)^{2}-\left(2 b \underline{y} q_{c}^{R}\right)^{2}\right)\right),
\end{aligned}
$$

where

$$
\begin{aligned}
\left(2 b \bar{y} q_{c}^{N R}\right)^{2}-\left(a-h-c_{p}\right)^{2}= & \left(2 b \bar{y} q_{c}^{N R}+\left(a-h-c_{p}\right)\right)\left(2 b \bar{y} q_{c}^{N R}-\left(a-h-c_{p}\right)\right) \\
= & \left(2 b \bar{y} q_{c}^{N R}+\left(a-h-c_{p}\right)\right) \frac{\bar{y}}{\theta \bar{y}^{2}+(1-\theta) \underline{y}}\left(\theta \bar{y}\left(h-p_{s}(\underline{y})+c_{f}\right)\right. \\
& \left.+(1-\theta) \underline{y}\left(\frac{a-p_{s}(\underline{y})+c_{f}-c_{p}}{\underline{y}}-\frac{a-h-c_{p}}{\bar{y}}\right)\right) \\
= & \left(2 b \bar{y} q_{c}^{N R}+\left(a-h-c_{p}\right)\right) \frac{B \bar{y}}{\theta \bar{y}^{2}+(1-\theta) \underline{y}} \leq 0 \\
\left(2 b \underline{y} q_{c}^{N R}\right)^{2}-\left(2 b \underline{y} q_{c}^{R}\right)^{2}= & 4 b^{2} \underline{y}\left(\left(q_{c}^{N R}\right)^{2}-\left(q_{c}^{R}\right)^{2}\right)<0 .
\end{aligned}
$$

Therefore, $E\left(\Pi\left(p_{c}^{N R}, q_{c}^{N R}\right)\right)-E\left(\Pi\left(p_{c}^{R}, q_{c}^{R}\right)\right)<0$.

If $B<C \leq 0<E<F$, then 


$$
\begin{aligned}
q_{c}^{N R}-q_{c}^{R}= & \frac{\theta \bar{y}(1-\theta) \underline{y}(\underline{y}-\bar{y})\left(a-p_{s}(\underline{y})+c_{f}-c_{p}\right)+(1-\theta)^{2} \underline{\underline{y}} \underline{\left(c_{m}+c_{f}\right)-\theta^{2} \bar{y}^{3}\left(h-p_{s}(\bar{y})+c_{f}\right)}}{2 b \theta(1-\theta) \bar{y}^{2} \underline{y}} \\
< & \frac{\theta \bar{y}(\underline{y}-\bar{y})\left(a-p_{s}(\underline{y})+c_{f}-c_{p}\right)+(1-\theta) \underline{y}\left(c_{m}+c_{f}\right)+\theta \bar{y}^{2}\left(a-p_{s}(\underline{y})+c_{f}-c_{p}-(\underline{y} / \bar{y})\left(a-h-c_{p}\right)\right)}{2 b \theta \bar{y}^{2} \underline{y}} \\
< & \frac{\theta \bar{y}(\underline{y}-\bar{y})\left(a-p_{s}(\underline{y})+c_{f}-c_{p}\right)-\theta \bar{y} \underline{y}\left(a-p_{s}(\underline{y})+c_{f}-c_{p}-(\bar{y} \underline{y})\left(a-p_{s}(\underline{y})-c_{m}-c_{p}\right)\right)+\theta \bar{y}^{2}\left(a-p_{s}(\underline{y})+c_{f}-c_{p}-(\underline{y} / \bar{y})\left(a-h-c_{p}\right)\right)}{2 b \theta \bar{y}^{2} \underline{y}} \\
= & \frac{1}{2 b}\left(\frac{a-p_{s}(\underline{y})-c_{m}-c_{p}}{y}-\frac{a-h-c_{p}}{\bar{y}}\right)=\frac{T A_{2}}{y}-\frac{T A_{1}}{\bar{y}}<0, \\
& E\left(\Pi\left(p_{c}^{N R}, q_{c}^{N R}\right)\right)-E\left(\Pi\left(p_{c}^{R}, q_{c}^{R}\right)\right) \\
= & \frac{\theta}{4 b}\left(2 b \bar{y} q_{c}^{N R}+\left(a-h-c_{p}\right)\right)\left(2 b \bar{y} q_{c}^{N R}-\left(a-h-c_{p}\right)\right)-\frac{1-\theta}{4 b}\left(2 b \underline{y} q_{c}^{R}+\left(a-p_{s}(\underline{y})-c_{m}-c_{p}\right)\right)\left(2 b \underline{y} q_{c}^{R}-\left(a-p_{s}(\underline{y})-c_{m}-c_{p}\right)\right),
\end{aligned}
$$

where

$$
\begin{aligned}
& 2 b \bar{y} q_{c}^{N R}+\left(a-h-c_{p}\right)=\left(a-p_{s}(\underline{y})+c_{f}-c_{p}\right)+\frac{(1-\theta) \underline{y}}{\theta \bar{y}}\left(c_{m}+c_{f}\right)+\left(a-h-c_{p}\right)>0, \\
& 2 b \bar{y} q_{c}^{N R}-\left(a-h-c_{p}\right)=\left(h-p_{s}(\underline{y})+c_{f}\right)+\frac{(1-\theta) \underline{y}}{\theta \bar{y}}\left(c_{m}+c_{f}\right)<0, \\
& 2 b \underline{y} q_{c}^{R}-\left(a-p_{s}(\underline{y})-c_{m}-c_{p}\right)=\frac{\theta \bar{y}}{(1-\theta) \underline{y}}\left(h-p_{s}(\bar{y})+c_{f}\right)+\left(c_{m}+c_{f}\right)>0, \\
& 2 b \underline{y} q_{c}^{R}+\left(a-p_{s}(\underline{y})-c_{m}-c_{p}\right)>2 b \underline{y} q_{c}^{R}-\left(a-p_{s}(\underline{y})-c_{m}-c_{p}\right)>0 .
\end{aligned}
$$

Therefore, $E\left(\Pi\left(p_{c}^{N R}, q_{c}^{N R}\right)\right)-E\left(\Pi\left(p_{c}^{R}, q_{c}^{R}\right)\right)<0$.

If $B<C \leq E \leq 0<F$, then

$$
\begin{aligned}
q_{c}^{N R}-q_{c}^{R} & =\frac{\theta \bar{y}(1-\theta) \underline{y}(\underline{y}-\bar{y})\left(a-p_{s}(\underline{y})+c_{f}-c_{p}\right)+\theta^{2} \bar{y}^{3}\left(p_{s}(\bar{y})-p_{s}(\underline{y})\right)+(1-\theta) \underline{y}\left(\theta \bar{y}^{2}+(1-\theta) \underline{y}\right)\left(c_{m}+c_{f}\right)}{2 b \theta \bar{y}^{2}\left(\theta \bar{y}^{2}+(1-\theta) \underline{y}\right)} \\
& \leq \frac{\theta \bar{y}(1-\theta) \underline{y}(\underline{y}-\bar{y})\left(a-p_{s}(\underline{y})+c_{f}-c_{p}\right)+\theta^{2} \bar{y}^{3}\left(p_{s}(\bar{y})-p_{s}(\underline{y})\right)-\theta \bar{y}\left(\theta \bar{y}^{2}+(1-\theta) \underline{y}\right)\left(a-p_{s}(\underline{y})+c_{f}-c_{p}-(\bar{y} / \underline{y})\left(a-p_{s}(\underline{y})-c_{m}-c_{p}\right)\right)}{2 b \theta \bar{y}^{2}\left(\theta \bar{y}^{2}+(1-\theta) \underline{y}\right)} \\
& =\frac{-\theta \bar{y}^{2}\left(a-p_{s}(\underline{y})+c_{f}-c_{p}\right)+\theta \bar{y}^{2} \bar{y} / \underline{y}\left(a-p_{s}(\underline{y})-c_{m}-c_{p}\right)-(1-\theta) \bar{y} \underline{y}\left(c_{m}+c_{f}\right)+\theta \bar{y}^{2}\left(p_{s}(\bar{y})-p_{s}(\underline{y})\right)}{2 b \bar{y}\left(\theta \bar{y}^{2}+(1-\theta) \underline{y}\right)} \\
& <\frac{-\theta \bar{y}^{2}\left(a-p_{s}(\underline{y})+c_{f}-c_{p}\right)+\theta \bar{y}^{2}(\bar{y} / \underline{y})\left(a-p_{s}(\underline{y})-c_{m}-c_{p}\right)+\theta \bar{y}^{2}\left(p_{s}(\bar{y})-p_{s}(\underline{y})\right)+\theta \bar{y}^{2}\left(a-p_{s}(\underline{y})+c_{f}-c_{p}-(\bar{y} / \underline{y})\left(a-p_{s}(\underline{y})-c_{m}-c_{p}\right)\right)}{2 b \bar{y}\left(\theta \bar{y}^{2}+(1-\theta) \underline{y}\right)}
\end{aligned}
$$

$<0$,

$$
E\left(\Pi\left(p_{c}^{N R}, q_{c}^{N R}\right)\right)-E\left(\Pi\left(p_{c}^{R}, q_{c}^{R}\right)\right)=\frac{1}{4 b}\left(\theta\left(\left(2 b \bar{y} q_{c}^{N R}\right)^{2}-\left(2 b \bar{y} q_{c}^{R}\right)^{2}\right)+(1-\theta)\left(\left(a-p_{s}(\underline{y})-c_{m}-c_{p}\right)^{2}-\left(2 b \underline{y} q_{c}^{R}\right)^{2}\right)\right),
$$


where

$$
\begin{aligned}
& \left(2 b \bar{y} q_{c}^{N R}\right)^{2}-\left(2 b \bar{y} q_{c}^{R}\right)^{2}=4 b^{2} \bar{y}^{2}\left(\left(q_{c}^{N R}\right)^{2}-\left(q_{c}^{R}\right)^{2}\right)<0, \\
& \left(a-p_{s}(\underline{y})-c_{m}-c_{p}\right)^{2}-\left(2 b \underline{y} q_{c}^{R}\right)^{2}=\left(a-p_{s}(\underline{y})-c_{m}-c_{p}+2 b \underline{y} q_{c}^{R}\right)\left(a-p_{s}(\underline{y})-c_{m}-c_{p}-2 b \underline{y} q_{c}^{R}\right) \\
= & \left(a-p_{s}(\underline{y})-c_{m}-c_{p}+2 b \underline{y} q_{c}^{R}\right)\left(a-p_{s}(\underline{y})-c_{m}-c_{p}-2 b \underline{y} \frac{\left.\theta \bar{y}\left(a-p_{s}(\bar{y})+c_{f}-c_{p}\right)+(1-\theta) \underline{y}\left(a-p_{s}(\underline{y})+c_{f}-c_{p}\right)\right)}{2 b\left(\theta \bar{y}^{2}+(1-\theta) \underline{y}\right)}\right) \\
= & \left(a-p_{s}(\underline{y})-c_{m}-c_{p}+2 b \underline{y} q_{c}^{R}\right) \frac{\theta \bar{y}^{2} \underline{y}\left(\left(a-p_{s}(\underline{y})-c_{m}-c_{p}\right) / \underline{y}-\left(a-p_{s}(\bar{y})+c_{f}-c_{p}\right) / \bar{y}\right)-(1-\theta) \underline{y}\left(c_{m}+c_{f}\right)}{\theta \bar{y}^{2}+(1-\theta) \underline{y}} \\
= & \left(a-p_{s}(\underline{y})-c_{m}-c_{p}+2 b \underline{y} q_{c}^{R}\right) \frac{-\underline{y} F}{\theta \bar{y}^{2}+(1-\theta) \underline{y}}<0 .
\end{aligned}
$$

Therefore,

If $B<C \leq E<F \leq 0$, then

$$
E\left(\Pi\left(p_{c}^{N R}, q_{c}^{N R}\right)\right)-E\left(\Pi\left(p_{c}^{R}, q_{c}^{R}\right)\right)<0 .
$$

$$
\begin{gathered}
q_{c}^{N R}-q_{c}^{R}=\frac{p_{s}(\bar{y})-p_{s}(\underline{y})}{2 b \bar{y}}<0, \\
E\left(\Pi\left(p_{c}^{N R}, q_{c}^{N R}\right)\right)-E\left(\Pi\left(p_{c}^{R}, q_{c}^{R}\right)\right)=b \theta \bar{y}^{2}\left(\left(q_{c}^{N R}\right)^{2}-\left(q_{c}^{R}\right)^{2}\right)<0 .
\end{gathered}
$$

(3) when $\left(T A_{2} / \underline{y}\right)<\left(T A_{1} / \bar{y}\right) \leq\left(T A_{3} / y\right)$ and $C>E$

If $0<B<E<C<F$, then

$$
\begin{gathered}
q_{c}^{N R}-q_{c}^{R}=\frac{\theta \bar{y}\left(p_{s}(\bar{y})-p_{s}(\underline{y})\right)}{2 b(1-\theta) \underline{y}}<0, \\
E\left(\Pi\left(p_{c}^{N R}, q_{c}^{N R}\right)\right)-E\left(\Pi\left(p_{c}^{R}, q_{c}^{R}\right)\right)=b(1-\theta) \underline{y}\left(\left(q_{c}^{N R}\right)^{2}-\left(q_{c}^{R}\right)^{2}\right)<0 .
\end{gathered}
$$

If $B \leq 0<E<C<F$, then

$$
q_{c}^{N R}-q_{c}^{R}=\frac{\theta \bar{y}(1-\theta) \underline{y}(\underline{y}-\bar{y})\left(a-p_{s}(\underline{y})+c_{f}-c_{p}\right)-\theta \bar{y}\left(\theta \bar{y}^{2}+(1-\theta) \underline{y} \underline{2}\right)\left(h-p_{s}(\bar{y})+c_{f}\right)}{2 b(1-\theta) \underline{y}\left(\theta \bar{y}^{2}+(1-\theta) \underline{y}\right)}<0,
$$

$E\left(\Pi\left(p_{c}^{N R}, q_{c}^{N R}\right)\right)-E\left(\Pi\left(p_{c}^{R}, q_{c}^{R}\right)\right)<0$. 
The proof is same with that in the situation $B \leq 0<C \leq E<F$ in (2).

If $B<E \leq 0<C<F$, then

$$
\begin{gathered}
q_{c}^{N R}-q_{c}^{R}=\frac{\theta \bar{y}\left(p_{s}(\bar{y})-p_{s}(\underline{y})\right)}{2 b\left(\theta \bar{y}^{2}+(1-\theta) \underline{y}\right)}<0, \\
E\left(\Pi\left(p_{c}^{N R}, q_{c}^{N R}\right)\right)-E\left(\Pi\left(p_{c}^{R}, q_{c}^{R}\right)\right)=b\left(\theta \bar{y}^{2}+(1-\theta) \underline{y}\right)\left(\left(q_{c}^{N R}\right)^{2}-\left(q_{c}^{R}\right)^{2}\right)<0 .
\end{gathered}
$$

If $B<E<C \leq 0<F$, then

$$
\begin{aligned}
q_{c}^{N R}-q_{c}^{R}= & \frac{\theta \bar{y}(1-\theta) \underline{y}(\underline{y}-\bar{y})\left(a-p_{s}(\underline{y})+c_{f}-c_{p}\right)+\theta^{2} \bar{y}^{3}\left(p_{s}(\bar{y})-p_{s}(\underline{y})\right)+(1-\theta) \underline{y}\left(\theta \bar{y}^{2}+(1-\theta) \underline{y}\right)\left(c_{m}+c_{f}\right)}{2 b \theta \bar{y}^{2}\left(\theta \bar{y}^{2}+(1-\theta) \underline{y}\right)}<0, \\
& E\left(\Pi\left(p_{c}^{N R}, q_{c}^{N R}\right)\right)-E\left(\Pi\left(p_{c}^{R}, q_{c}^{R}\right)\right)<0 .
\end{aligned}
$$

The proof is same with that in the situation

If $B<E<C<F \leq 0$, then

$B<C \leq E \leq 0<F$ in (2).

$$
\begin{gathered}
q_{c}^{N R}-q_{c}^{R}=\frac{p_{s}(\bar{y})-p_{s}(\underline{y})}{2 b \bar{y}}<0, \\
E\left(\Pi\left(p_{c}^{N R}, q_{c}^{N R}\right)\right)-E\left(\Pi\left(p_{c}^{R}, q_{c}^{R}\right)\right)=b \theta \bar{y}^{2}\left(\left(q_{c}^{N R}\right)^{2}-\left(q_{c}^{R}\right)^{2}\right)<0 .
\end{gathered}
$$

(4) when $\left(T A_{1} / \bar{y}\right)>\left(T A_{3} / y\right)$

If $0<C<F$, then

$$
\begin{gathered}
q_{c}^{N R}-q_{c}^{R}=\frac{\theta \bar{y}\left(p_{s}(\bar{y})-p_{s}(\underline{y})\right)}{2 b\left(\theta \bar{y}^{2}+(1-\theta) \underline{y}\right)}<0, \\
E\left(\Pi\left(p_{c}^{N R}, q_{c}^{N R}\right)\right)-E\left(\Pi\left(p_{c}^{R}, q_{c}^{R}\right)\right)=b(1-\theta) \underline{y}\left(\left(q_{c}^{N R}\right)^{2}-\left(q_{c}^{R}\right)^{2}\right)<0 .
\end{gathered}
$$

If $C \leq 0<F$, then

$$
\begin{aligned}
q_{c}^{N R}-q_{c}^{R}= & \frac{\theta \bar{y}(1-\theta) \underline{y}(\underline{y}-\bar{y})\left(a-p_{s}(\underline{y})+c_{f}-c_{p}\right)+\theta^{2} \bar{y}^{3}\left(p_{s}(\bar{y})-p_{s}(\underline{y})\right)+(1-\theta) \underline{y}\left(\theta \bar{y}^{2}+(1-\theta) \underline{y}\right)\left(c_{m}+c_{f}\right)}{2 b \theta \bar{y}^{2}\left(\theta \bar{y}^{2}+(1-\theta) \underline{y}\right)}<0, \\
E\left(\Pi\left(p_{c}^{N R}, q_{c}^{N R}\right)\right)-E\left(\Pi\left(p_{c}^{R}, q_{c}^{R}\right)\right)<0 . &
\end{aligned}
$$




$$
\begin{gathered}
q_{c}^{N R}-q_{c}^{R}=\frac{\theta \bar{y}\left(p_{s}(\bar{y})-p_{s}(\underline{y})\right)}{2 b \theta \bar{y}^{2}}<0, \\
E\left(\Pi\left(p_{c}^{N R}, q_{c}^{N R}\right)\right)-E\left(\Pi\left(p_{c}^{R}, q_{c}^{R}\right)\right)=b \theta \bar{y}^{2}\left(\left(q_{c}^{N R}\right)^{2}-\left(q_{c}^{R}\right)^{2}\right)<0 .
\end{gathered}
$$

Above all, we have $q_{c}^{N R}<q_{c}^{R}$ and $E\left(\Pi\left(p_{c}^{N R}, q_{c}^{N R}\right)\right)<$ $E\left(\Pi\left(p_{c}^{R}, q_{c}^{R}\right)\right)$.

\section{Data Availability}

The data used to support the findings of this study are included within the study, and they are true and reliable. The data are available from the corresponding author upon request.

\section{Conflicts of Interest}

The authors declare that there are no conflicts of interest regarding the publication of this study.

\section{Acknowledgments}

This research was funded by the National Natural Science Foundation of China (grant no. 71601097), the Fundamental Research Funds for the Central Universities (grant no. SKYC2020003), the National Natural Science Foundation of China (grant no. 71973066), a project funded by the Priority Academic Program Development of Jiangsu Higher Education Institutions (PAPD), the Humanities and Social Sciences Fund of Ministry of Education of China (grant no. 20YJC630131), and the Social Science Fund of Jiangsu Province, China (grant nos. 20GLB015 and 17ZTA004).

\section{References}

[1] FAO, FAQ: What is Contract Farming? Contract Farming Resource Centre, Food and Agriculture Organization of the United Nations, Rome, Italy, http://www.fao.org/ag/ags/ contract-farming/faq/en/.

[2] C. B. Barrett, M. E. Bachke, M. F. Bellemare, H. C. Michelson, S. Narayanan, and T. F. Walker, "Smallholder participation in contract farming: comparative evidence from five countries," World Development, vol. 40, no. 4, pp. 715-730, 2012.

[3] H. H. Wang, Y. Wang, and M. S. Delgado, “The transition to modern agriculture: contract farming in developing economies," American Journal of Agricultural Economics, vol. 96, no. 5, pp. 1257-1271, 2014.

[4] W. T. Huh, S. Athanassoglou, and U. Lall, "Contract farming with possible reneging in a developing country: can it work?" IIMB Management Review, vol. 24, pp. 187-202, 2012.

[5] J. F. M. Swinnen, M. Sadler, and A. Vandeplas, "“Contracting, competition and rent distribution in supply chains: theory and empirical evidence" from central Asia," in Global Supply Chains, Standards and the Poor: How the Globalization of Food Systems and Standards Affects Rural Development and
Poverty, J. F. M. Swinnen, Ed., pp. 75-88, Cromwell Press, Trowbridge, UK, 2007.

[6] M. V. Chiriacò, G. Grossi, S. Castaldi, and R. Valentini, "The contribution to climate change of the organic versus conventional wheat farming: a case study on the carbon footprint of wholemeal bread production in Italy," Journal of Cleaner Production, vol. 153, pp. 309-319, 2017.

[7] R. Holst, X. Yu, and C. Grün, "Climate change, risk and grain yields in China," Journal of Integrative Agriculture, vol. 12, no. 7, pp. 1279-1291, 2013.

[8] H. Albers, C. Gornott, and S. Hüttel, "How do inputs and weather drive wheat yield volatility? The example of Germany," Food Policy, vol. 70, pp. 50-61, 2017.

[9] A. Gobin, "Weather related risks in Belgian arable agriculture," Agricultural Systems, vol. 159, pp. 225-236, 2018.

[10] FAO, The Impact of Disasters and Crises on Agriculture and Food Security, 2018, https://www.fao.org/3/I8656EN/i8656en. pdf.

[11] H. Wang, Y. Zhang, and L. Wu, "Is contract farming a risk management instrument for Chinese farmers?" China Agricultural Economic Review, vol. 3, no. 4, pp. 489-505, 2011.

[12] D. Wuepper and J. Sauer, "Explaining the performance of contract farming in Ghana: the role of self-efficacy and social capital," Food Policy, vol. 62, pp. 11-27, 2016.

[13] H. C. Michelson, "Small farmers, NGOs, and a Walmart world: welfare effects of supermarkets operating in Nicaragua," American Journal of Agricultural Economics, vol. 95, no. 3, pp. 628-649, 2013.

[14] M. F. Bellemare and L. Novak, "Contract farming and food security," American Journal of Agricultural Economics, vol. 99, no. 2, pp. 357-378, 2017.

[15] G. Ton, W. Vellema, S. Desiere, S. Weituschat, and M. D'Haese, "Contract farming for improving smallholder incomes: what can we learn from effectiveness studies?" World Development, vol. 104, pp. 46-64, 2018.

[16] M. F. Bellemare and J. R. Bloem, "Does contract farming improve welfare? A review," World Development, vol. 112, pp. 259-271, 2018.

[17] B. Niu, D. Jin, and X. Pu, "Coordination of channel members' efforts and utilities in contract farming operations," European Journal of Operational Research, vol. 255, no. 3, pp. 869-883, 2016.

[18] A. Federgruen, U. Lall, and A. S. Şimşek, "Supply chain analysis of contract farming," Manufacturing \& Service Operations Management, vol. 21, no. 2, pp. 361-378, 2019.

[19] C. A. Yano and H. L. Lee, "Lot sizing with random yields: a review," Operations Research, vol. 43, no. 2, pp. 311-334, 1995.

[20] A. Aslani, A. A. Taleizadeh, and S. Zanoni, "An EOQ model with partial backordering with regard to random yield: two strategies to improve mean and variance of the yield," 
Computers \& Industrial Engineering, vol. 112, pp. 379-390, 2017.

[21] P. C. Jones, T. J. Lowe, R. D. Traub, and G. Kegler, "Matching supply and demand: the value of a second chance in producing hybrid seed corn," Manufacturing \& Service Operations Management, vol. 3, no. 2, pp. 122-137, 2001.

[22] B. Kazaz, "Production planning under yield and demand uncertainty with yield-dependent cost and price," Manufacturing \& Service Operations Management, vol. 6, no. 3, pp. 209-224, 2004.

[23] B. Kazaz and S. Webster, "The impact of yield-dependent trading costs on pricing and production planning under supply uncertainty," Manufacturing \& Service Operations Management, vol. 13, no. 3, pp. 404-417, 2011.

[24] B. Tan and N. Çömden, "Agricultural planning of annual plants under demand, maturation, harvest, and yield risk," European Journal of Operational Research, vol. 220, no. 2, pp. 539-549, 2012.

[25] B. Kazaz and S. Webster, "Technical note-price-setting newsvendor problems with uncertain supply and risk aversion," Operations Research, vol. 63, no. 4, pp. 807-811, 2015.

[26] W. T. Huh and U. Lall, "Optimal crop choice, irrigation allocation, and the impact of contract farming," Production and Operations Management, vol. 22, pp. 1126-1143, 2013.

[27] A. Golmohammadi and E. Hassini, "Capacity, pricing and production under supply and demand uncertainties with an application in agriculture," European Journal of Operational Research, vol. 275, no. 3, pp. 1037-1049, 2019.

[28] G. H. Sun, "Research on the fresh agricultural product supply chain coordination with supply disruptions," Discrete Dynamics in Nature and Society, vol. 2013, Article ID 416790, 9 pages, 2013

[29] E. Cao, X. Zhou, and K. Lü, "Coordinating a supply chain under demand and cost disruptions," International Journal of Production Research, vol. 53, no. 12, pp. 3735-3752, 2015.

[30] J. Heydari, K. Govindan, H. R. E. Nasab, and A. A. Taleizadeh, "Coordination by quantity flexibility contract in a two-echelon supply chain system: effect of outsourcing decisions," International Journal of Production Economics, vol. 22, Article ID 107586, 2020.

[31] Z. Chen, J. Li, Z. Liu, and Z. Zheng, "Incentive contracts for capacity restoration under risk of supply disruption," IEEE Transactions on Engineering Management, vol. 66, no. 4, pp. 746-762, 2019.

[32] R. M. Difrancesco, P. Meena, and R. Tibrewala, "Buyback and risk-sharing contracts to mitigate the supply and demand disruption risks," European Journal of Industrial Engineering, vol. 15, no. 4, pp. 550-581, 2021.

[33] A. Aslani and J. Heydari, "Transshipment contract for coordination of a green dual-channel supply chain under channel disruption," Journal of Cleaner Production, vol. 223, pp. 596-609, 2019.

[34] J. Heydari, A. Aslani, and A. Sabbaghnia, "A collaborative scenario-based decision model for a disrupted dual-channel supply chain: Benchmarking against the centralized structure," Benchmarking: An International Journal, vol. 27, pp. 933-957, 2020.

[35] F. Y. Chen and C. A. Yano, "Improving supply chain performance and managing risk under weather-related demand uncertainty," Management Science, vol. 56, no. 8, pp. 1380-1397, 2010.

[36] F. Gao, O. C. Demirag, and F. Y. Chen, "Early sales of seasonal products with weather-conditional rebates," Production and Operations Management, vol. 21, no. 4, pp. 778-794, 2012.
[37] O. C. Demirag, "Performance of weather-conditional rebates under different risk preferences," Omega, vol. 41, no. 6, pp. 1053-1067, 2013.

[38] F. Gao, F. Y. Chen, and X. Chao, "Joint optimal ordering and weather hedging decisions: mean-CVaR model," Flexible Services and Manufacturing Journal, vol. 23, no. 1, pp. 1-25, 2011.

[39] X. Y. Zeng and X. X. Guo, "Extreme weather, grain yield fluctuation, and weather risk management in agriculture," Jiangsu Agricultural Sciences, vol. 45, pp. 306-309, 2017, in Chinese.

[40] Z. H. Lv, S. S. Ding, and R. L. Lu, "Climate suitability of crops in China: research progress," Chinese Agricultural Science Bulletin, vol. 36, pp. 78-84, 2020, in Chinese. 